\title{
Fisiologia de espécies florestais da Amazônia: fotossíntese, respiração e relações hídricas
}

\author{
Ricardo Antonio Marenco ${ }^{1}$, Saul Alfredo Antezana-Vera ${ }^{2}$, Paula Romenya dos Santos Gouvêa ${ }^{3}$, \\ Miguel Angelo Branco Camargo ${ }^{4}$, Marcilia Freitas de Oliveira ${ }^{5}$, Joanne Kelly da Silva Santos ${ }^{6}$ \\ http://dx.doi.org/10.1590/0034-737X201461000004
}

\begin{abstract}
RESUMO
A bacia amazônica tem mais de seis milhões de quilômetros quadrados e abriga a maior floresta tropical do mundo, sendo particularmente importante pela sua biodiversidade e pelo seu papel na ciclagem de água e carbono. Fotossíntese, condutância estomática e fluxo de seiva de espécies florestais da Amazônia apresentam variação ao longo do dia seguindo a variação diurna observada na irradiância, temperatura e o déficit de pressão de vapor. Em decorrência da fotorrespiração, cerca de $25 \%$ do carbono fixado é retornado para a atmosfera. Os aumentos na concentração de $\mathrm{CO}_{2}$ na atmosfera previstos para as próximas décadas poderão apresentar efeito positivo na assimilação de carbono deste ecossistema florestal. Em comparação à época chuvosa, redução da umidade do solo e aumento no déficit de pressão de vapor (associado à baixa umidade do ar e alta temperatura) favorecem o fechamento dos estômatos em detrimento da fotossíntese. Desse modo, em comparação com a estação chuvosa, a fotossíntese líquida é menor no período seco. No geral, na Amazônia as árvores que atingem o dossel da floresta crescem a taxas maiores na época chuvosa. Exceto em anos de menor precipitação, o ecossistema florestal atua como sumidouro de carbono na época chuvosa. Mais estudos são necessários para determinar como e de que forma fatores específicos do ambiente físico influenciam a assimilação de carbono e o crescimento de árvores nos diversos grupos funcionais na Amazônia.
\end{abstract}

Palavras-chave: condutância estomática; potencial hídrico, fluxo de seiva, ecossistema florestal, fluxo noturno de seiva.

\section{ABSTRACT}

\section{Physiology of Amazon tree species: photosynthesis, respiration and water relations}

The Amazon basin comprises more than six million square kilometers and holds the largest tropical forest in the world. It is particularly important for its biodiversity and for its role in the cycling of water and carbon. Photosynthesis, stomatal conductance and sap flow of Amazon tree species show variation throughout the day following the diurnal variation of irradiance, temperature and vapor pressure deficit. Due to photorespiration, at least $25 \%$ of the fixed carbon is returned to the atmosphere. Thus, increases in atmospheric $\mathrm{CO}_{2}$ concentration in the decades to come may have a positive effect on carbon assimilation of the forest ecosystem. Compared to the rainy season, low water

Recebido para publicação em 21/08/2014 e aprovado em 16/10/2014.

'Engenheiro-Agrônomo, Doutor. Instituto Nacional de Pesquisas da Amazônia (INPA), Avenida André Araújo, 2936, 69067-375, Manaus, Amazonas, Brasil. rmarenco@inpa.gov.br (autor correspondente).

${ }^{2}$ Biólogo, Mestre. Programa de Pós-Graduação em Botânica, Instituto Nacional de Pesquisas da Amazônia (INPA), Avenida André Araújo, 2936, 69067-375, Manaus, Amazonas, Brasil. saulantve@hotmail.com

${ }^{3}$ Bióloga. Programa de Pós-Graduação em Agricultura no Trópico Úmido, Instituto Nacional de Pesquisas da Amazônia (INPA), Avenida André Araújo, 2936, 69067-375, Manaus, Amazonas, Brasil. paulagouvea.bio@gmail.com

${ }^{4}$ Biólogo, Mestre. Programa de Pós-Graduação em Botânica, Instituto Nacional de Pesquisas da Amazônia (INPA), Avenida André Araújo, 2936, 69067-375, Manaus, Amazonas, Brasil. mg.branco21@gmail.com

${ }^{5}$ Bióloga. Programa de Pós-Graduação em Botânica, Instituto Nacional de Pesquisas da Amazônia (INPA), Avenida André Araújo, 2936, 69067-375, Manaus, Amazonas, Brasil.marciliabot@gmail.com

${ }^{6}$ Estudante de Graduação. Escola Superior Batista do Amazonas, Instituto Nacional de Pesquisas da Amazônia (INPA), Avenida André Araújo, 2936, 69067-375, Manaus, Amazonas, Brasil. joanne.kelly8@gmail.com 
availability in dry season and increased vapor pressure deficit (low humidity and high temperature) during the dry period induce stomata closure, which eventually leads to photosynthesis decline. Several studies have shown that Amazonian trees that reach the forest canopy grow at higher rates in the rainy season. Except in years with low rainfall, the forest ecosystem is a carbon sink in the rainy season. More studies are needed to determine how and in what extent specific factors of the physical environment influence carbon assimilation and growth of trees from different functional groups in the Amazon region.

Key words: stomatal conductance, water potential, sap flux, forest ecosystem, nocturnal sap flux.

\section{INTRODUÇÃO}

A floresta Amazônica é a maior floresta tropical do mundo, sendo particularmente importante devido ao seu papel na ciclagem de água e carbono (Saatchi et al., 2007) e na conservação da biodiversidade do planeta. Houghton et al. (2000) estimam que a maior parte da Amazônia tem em média $21,0 \mathrm{~kg}(\mathrm{C}) \mathrm{m}^{-2}$, variando entre 14 e $23 \mathrm{~kg}$ (C) $\mathrm{m}^{-2}$. De forma geral estima-se que a Amazônia armazena $86 \mathrm{Pg}$ de carbono (um petagrama equivale a um bilhão de toneladas) na biomassa total [i.e., parte aérea, raízes e árvores mortas (Saatchi et al., 2007)], sendo que que aproximadamente $20 \%$ da biomassa total corresponde à biomassa abaixo do solo (Houghton et al., 2000).

Em média 50\% da precipitação que ocorre na região amazônica é reciclada via transpiração (Salati, 1987; Fisher et al., 2009). Estima-se que na Amazônia, a produção primária líquida, $P_{\mathrm{PL}}$ (i.e. tecido novo formado por unidade de tempo: ganho de biomassa em tronco, raízes e galhos, produção de folhas, flores e frutos ) oscile ente 0,1 e $0,5 \mathrm{~kg}(\mathrm{C}) \mathrm{m}^{-2}$ ano $^{-1}$ (Malhi et al., 1998). A $P_{\mathrm{PL}}$ das florestas tropicais pode ser limitada por vários fatores, incluindo a disponibilidade de nutrientes (Vitousek et al., 2010), radiação solar (Graham et al., 2003) e teor de água do solo (Wagner et al., 2012).

De acordo com a classificação climática de Köppen a maior parte da região amazônica possui clima tropical do tipo $A_{\mathrm{f}}$ (tropical sem estação seca severa, $51 \%$ da região) ou tropical monsônico, $A_{\mathrm{w}}$, tropical com inverno seco, 45\% da região (Alvares et al., 2013). A precipitação anual varia de 2100 a $2960 \mathrm{~mm}$, a temperatura média anual oscila entre 25,5 e $26,2^{\circ} \mathrm{C}$ e a radiação solar de 15,6 a $16,6 \mathrm{MJ} \mathrm{m}^{-2} \mathrm{dia}^{-1}$ (Malhi \& Wright, 2004). Na bacia amazônica em geral, os meses mais secos (déficit hídrico climatológico) ocorrem de julho a novembro (déficit de 80 a $120 \mathrm{~mm}$ por mês), sendo setembro o mês de maior déficit (Gatti et al., 2014).

A maior parte dos solos da Amazônia são altamente intemperizados e pobres em nutrientes (Sanchez, 1977; Quesada et al., 2012). Uma hipótese que tem prevalecido é que a disponibilidade de alguns elementos, particularmente fósforo, limita a produtividade da floresta na Amazônia (Townsend et al., 2007; Vitousek et al., 2010;
Townsend et al., 2011). Alguns fatores que podem influenciar na produtividade primária bruta, $A_{\mathrm{B}}$ (somatório da respiração total e da $P_{\mathrm{PL}}$ ) de florestas tropicais, como a Amazônia, incluem temperatura, precipitação, radiação solar incidente, ocorrência de eventos climáticos extremos (e.g. El Niño), concentração de $\mathrm{CO}_{2}$ na atmosfera, disponibilidade de nutrientes (e.g., nitrogênio e fósforo) e mudanças no uso da terra (Lewis et al., 2009). Neste artigo maior ênfase é dada aos aspectos da fisiologia de árvores relacionados com a fotossíntese, respiração e relações hídricas do vegetal.

\section{FOTOSSÍNTESE}

A fotossíntese é o mecanismo pelo qual plantas e algumas bactérias sintetizam compostos orgânicos utilizando a luz como fonte de energia. A energia fixada via fotossíntese é armazenada em compostos orgânicos os quais são utilizados no metabolismo celular da planta. A exceção da energia fixada por microrganismos quimiossintetizadores, a energia fixada pelas plantas durante a fotossíntese constitui a base da cadeia alimentar do planeta. Fatores internos e externos têm influencia na capacidade fotossintética da planta. Os fatores externos incluem disponibilidade de água e nutrientes, temperatura, irradiância e concentração de $\mathrm{CO}_{2}$. Já os fatores internos incluem fatores genéticos propriamente ditos, espessura da lâmina foliar, teor de clorofila, idade da folha e em algumas plantas ritmos endógenos associados ao funcionamento celular. Desta forma, folhas em fase inicial de crescimento ou em fase de senescência têm taxas menores de fotossíntese do que folhas maduras completamente expandidas.

\section{Irradiância}

Em nível de folha a fotossíntese aumenta com a irradiância até atingir o ponto de saturação, $P_{\mathrm{S}}$ (Figura 1A). A partir desse ponto, aumentos na irradiância não causam aumentos na fotossíntese. A irradiância de compensação $\left(P_{\mathrm{C}}\right)$ é atingida quando a quantidade de carbono fixado via fotossíntese é igual a quantidade de carbono perdido pela respiração (Figura 1B). Diversas equações têm sido sugeridas para descrever a fotossíntese 
da folha em função da irradiância (Lobo et al., 2013). Em plantas do tipo $\mathrm{C}_{3}$ como as árvores da Amazônia, a resposta ao aumento da irradiância varia em função da concentração de $\mathrm{CO}_{2}$, como ilustrado na Figura 1.

Um parâmetro importante na resposta da fotossíntese à irradiância é a "eficiência quântica da fotossíntese", normalmente representada pela letra grega $\Phi$ (phi). Esse parâmetro representa a quantidade molar de $\mathrm{CO}_{2}$ fixado por mol de fóton absorvido. Em diversas espécies na base da luz incidente, $\Phi_{\mathrm{I}}$ varia de 0,077 a 0,098 , já na base da luz absorvida $\left(\Phi_{\mathrm{A}}\right)$ o rendimento médio de plantas do tipo $\mathrm{C}_{3}$ varia entre 0,090 e 0,11 , isto porque na maioria das plantas a absorbância média da folha $(\alpha)$ é de 0,84 (Bjorkman \& Demmig, 1987).

Os valores de $\Phi$ são determinados em baixas irradiância, geralmente entre $10 \mathrm{e} 60 \mu \mathrm{mol} \mathrm{m}^{-2} \mathrm{~s}^{-1}$. O valor em irradiância zero normalmente é excluído por causa do efeito Kok (Villar et al., 1994). Devido às perdas de energia na forma de calor, $\Phi$ diminui expressivamente com a irradiância (Lobo et al., 2013).
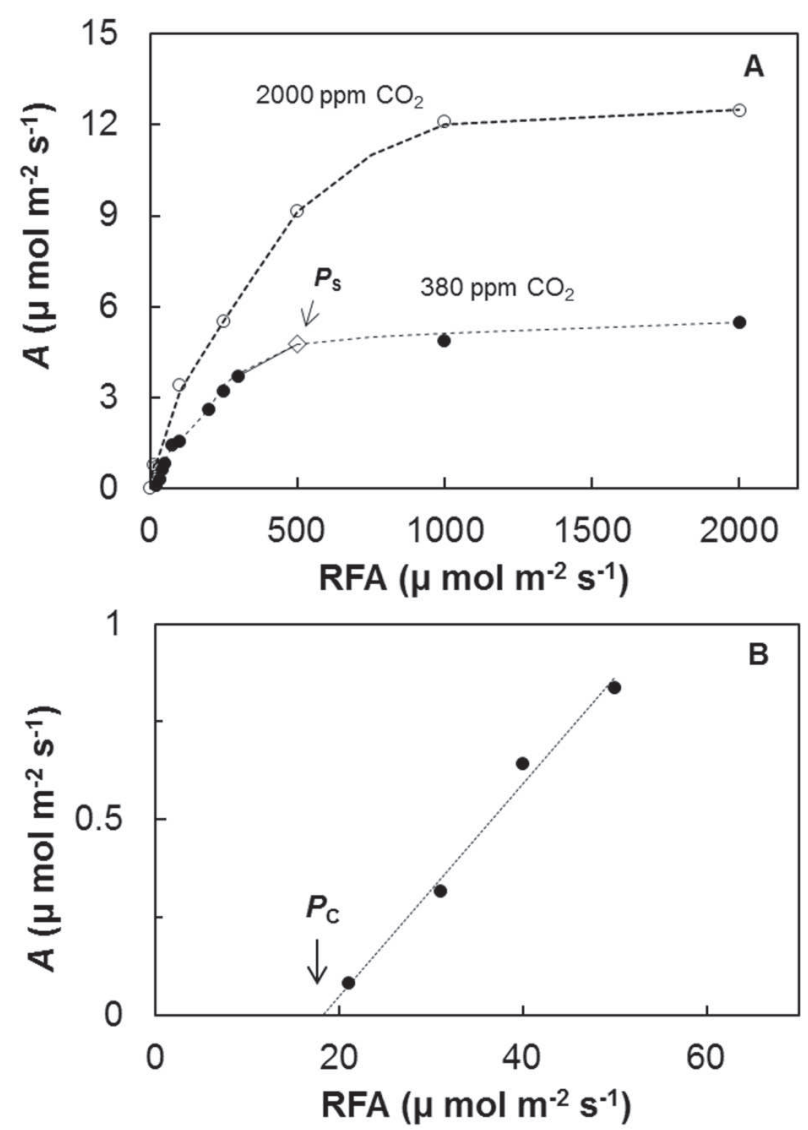

Figura 1. Resposta da fotossíntese $(A)$ à radiação fotossinteticamente ativa (RFA) em concentração ambiente (380 ppm) e 2000 ppm de $\mathrm{CO}_{2}$ na câmera foliar (A). Painel B mostra $A$ em função de RFA em baixa irradiância e $380 \mathrm{ppm}$ de $\mathrm{CO}_{2}$. $P_{\mathrm{S}}$ : ponto de saturação; $P_{\mathrm{C}}$ : ponto de compensação. Dados coletados em uma arvoreta de Minquartia guianensis (aclimatada à sombra) utilizando um medidor de fotossíntese (Li-6400, Li-Cor, EUA, dados originais não publicados).
$\mathrm{Na}$ base da luz incidente, o teor de clorofila tem efeito em $\Phi_{\mathrm{I}}$. Isto por causa do efeito da clorofila na absorbância da folha. Por exemplo, um aumento no teor de clorofila de 174 para $697 \mathrm{mg} \mathrm{m}^{-2}$ causa aumento de 28\% na absorbância da folha (Bjorkman \& Demmig, 1987). A absorbância da folha $(\alpha)$ pode ser calculada a partir dos teores de clorofila da folha: sendo $\alpha=\mathrm{Chl} /$ $\mathrm{Chl}+76$ ); em que: Chl representa o conteúdo de clorofila em $\mu \mathrm{mol} \mathrm{m}^{-2}$ por unidade de área (Evans \& Poorter, 2001).

Devido à fotorrespiração, a concentração de oxigênio no entorno da folha tem efeito marcante nos valores de $\Phi$. Há efeito da temperatura na fotorrespiração (Marenco \& Lopes, 2009), por isso em condições de $\mathrm{CO}_{2}$ ambiente os valores de $\Phi$ diminuem com aumento da temperatura (Figura 2).

A eficiência quântica da fotossíntese $(\Phi)$ não deve ser confundida com a eficiência fotoquímica máxima do fotossistema II definida pela relação $\mathrm{F}_{\mathrm{v}} / \mathrm{F}_{\mathrm{M}}$. Em que, $\mathrm{F}_{\mathrm{v}}$ denota a fluorescência variável e $F_{M}$ a fluorescência máxima, $\mathrm{F}_{\mathrm{V}}=\left(\mathrm{F}_{\mathrm{M}}-\mathrm{F}_{0}\right) / \mathrm{F}_{\mathrm{M}}$, sendo $\mathrm{F}_{0}$ a fluorescência mínima da folha adaptada ao escuro.

A relação $\mathrm{F}_{\mathrm{v}} / \mathrm{F}_{\mathrm{M}}$ reflete a proporção de energia luminosa absorvida pelas clorofilas (no fotossistema II) que é utilizada no transporte de elétrons. Em razão disso há estreita correlação $(r=0,98)$ entre os valores da relação $\mathrm{F}_{\mathrm{V}} / \mathrm{F}_{\mathrm{M}}$ e os valores de $\Phi$ (Bjorkman \& Demmig, 1987).

Em folhas de dossel de árvores da Amazônia os valores da relação $\mathrm{F}_{\mathrm{v}} / \mathrm{F}_{\mathrm{M}}$ variam ao longo do dia, de valores

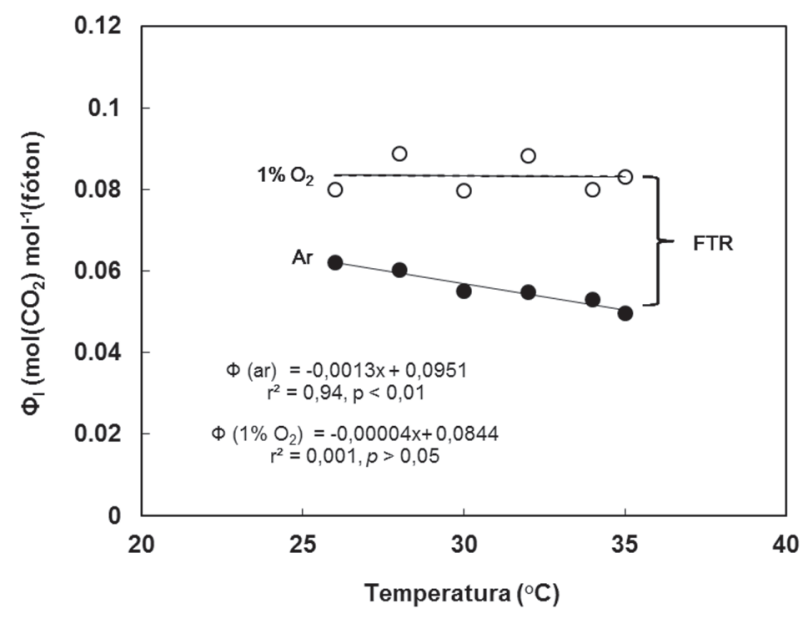

Figura 2. Variação do rendimento quântico aparente $(\Phi)$ em função da temperatura, em $\operatorname{ar}\left(21,8 \%\right.$ de $\mathrm{O}_{2}$, círculo cheio) e em baixa concentração de oxigênio $\left(1 \%\right.$ de $\mathrm{O}_{2}$ e $99 \% \mathrm{~N}_{2}$, círculo vazio). Observe que em ar, $\Phi$ diminui com aumento da temperatura. Para uma mesma temperatura, a diferença entre dois pontos mostra o efeito da fotorrespiração (FTR). Dados coletados em uma arvoreta de Minquartia guianensis utilizando um medidor de fotossíntese (Li-6400, Li-Cor, EUA, dados originais não publicados). 
próximos de 0,8 ao amanhecer até 0,7 nos horários do meio dia, observando-se recuperação ao final da tarde como pode ser observado na Figura 3. A pouca redução na relação $\mathrm{F}_{\mathrm{V}} / \mathrm{F}_{\mathrm{M}}$ mostra que folhas de dossel estão adaptadas às condições de radiação solar intensa que prevalecem durante o dia. Porém, mudas e arvoretas (árvores na fase juvenil) submetidas à radiação solar intensa sofrem fotoinibição da fotossíntese (Azevedo \& Marenco, 2012) e em casos de exposição prolongada foto-oxidação foliar (Magalhães et al., 2009). Em árvores e arvoretas da Amazônia, as taxas de fotossíntese variam ao longo do dia, observando-se os maiores valores na parte da manhã e os menores na parte da tarde (Malhi et al., 1998; Doughty et al., 2006; Nascimento \& Marenco, 2013; Marenco et al., 2014).

Em Inga capitata a fotossíntese aumenta na parte da manhã até atingir um ponto máximo que ocorre pouco antes do meio dia, declinando de forma constante no período da tarde (Figura 4). Um padrão similar é observado em Coussapoa orthoneura e Protium opacum (Figura 5). Independente da espécie há estreita relação entre fotossíntese e condutância estomática $\left(g_{\mathrm{s}}\right)$, conforme ilustrado na Figura 6. Deve-se mencionar, entretanto, que embora a maioria das espécies siga esse padrão diurno, há diferença nos valores absolutos entre as espécies e árvores de uma mesma espécie em função de

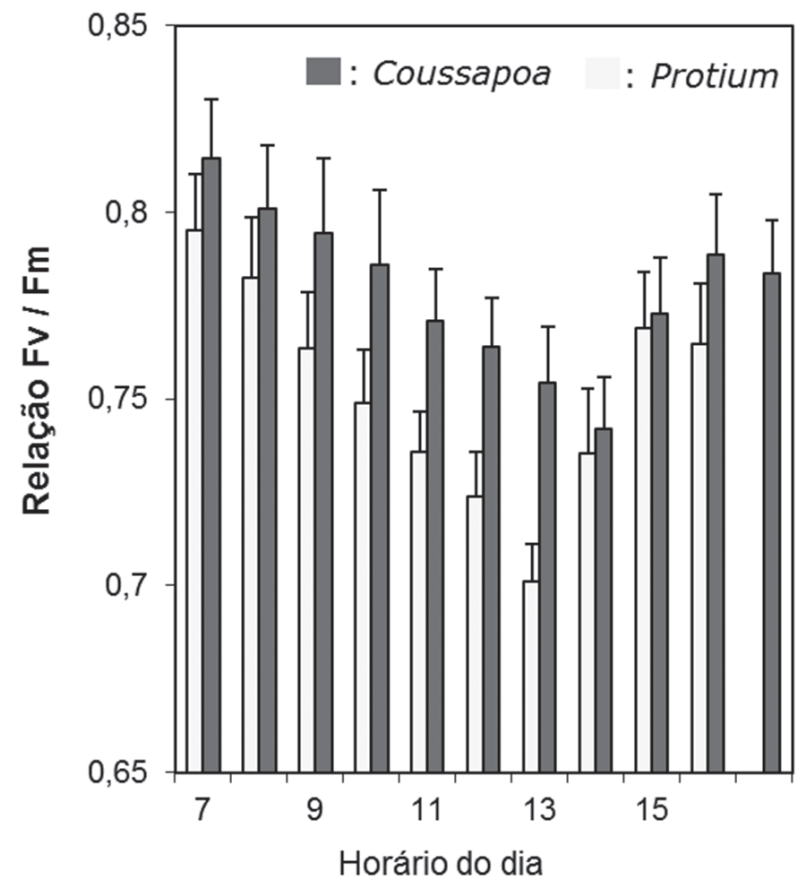

Figura 3. Variação na relação $F_{v} / F_{m}$ em função da horário do dia em árvores de Coussapoa orthoneura (Cecropiaceae) e Protium opacum (Burseraceae). O dossel (22 a $27 \mathrm{~m}$ de altura) foi acessado utilizando uma torre de observação localizada na Reserva ZF2 do INPA $\left(02^{\circ} 35^{\prime} 21^{\prime \prime} \mathrm{S}, 60^{\circ} 06^{\prime} 53^{\prime \prime} \mathrm{W}\right)$. Adaptado de Marenco et al. (2007). características foliares, tais como a massa foliar específica (Azevedo \& Marenco, 2012).

No período diurno a condutância estomática responde às mudanças na diferença de pressão de vapor entre a folha e o ar (DPV). No geral os estômatos fecham à proporção que o DPV aumenta (Lloyd et al., 1995, Marenco \& Lopes, 2009). A abertura dos estômatos depende da atividade de uma bomba de prótons e da condutância de canais proteicos localizados na membrana das células guarda (Shimazaki et al., 2007; Hozain et al., 2010). Assim, na ausência de restrição hídrica, a alta umidade do ar e o aumento da temperatura dentro de uma faixa moderada $\left(23-28^{\circ} \mathrm{C}\right) \mathrm{le}-$ vam a um aumento da condutância do mesofilo, atividade da Rubisco e do transporte de elétrons (Warren, 2008) e como resultado aumenta a condutância dos estômatos via efeito de retroalimentação da concentração de $\mathrm{CO}_{2}$ intercelular na abertura dos estômatos. Por isso, dependendo das condições ambientais, nas primeiras horas da manhã quando o potencial hídrico da folha é maior, $g_{\mathrm{s}}$ pode aumentar independente do aumento do DPV. Porém, quando a temperatura e o DPV

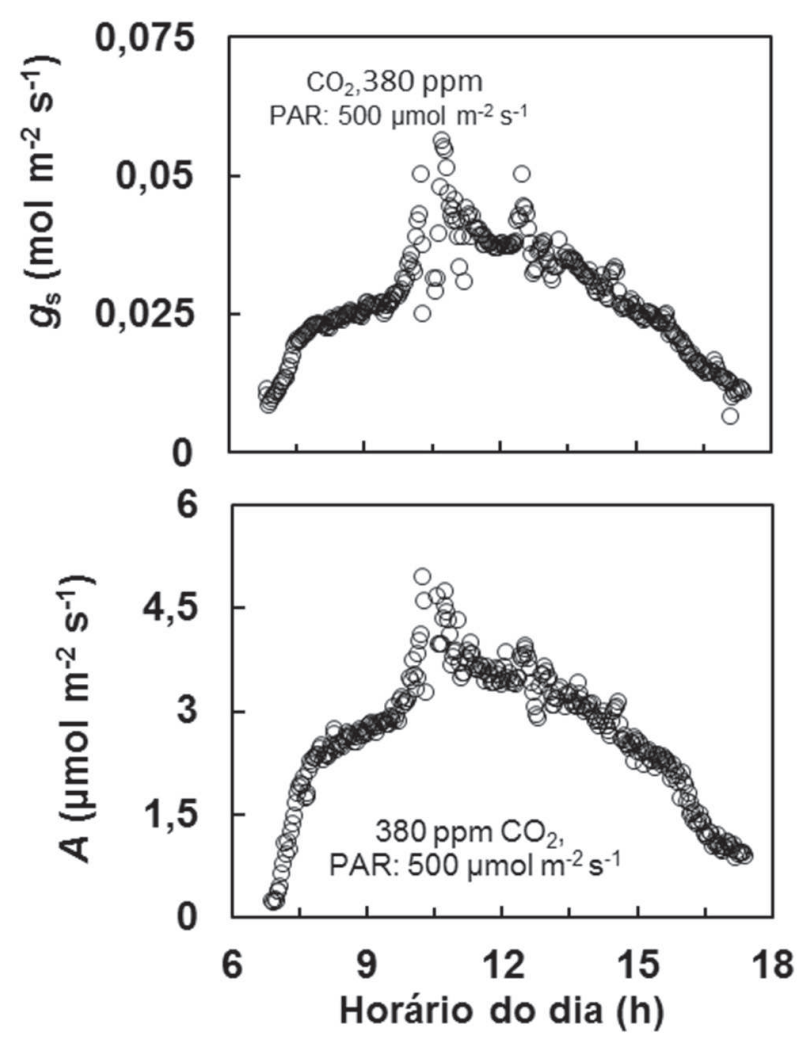

Figura 4. Variação diurna da fotossíntese $(A)$ e condutância estomática $\left(g_{\mathrm{s}}\right)$ em folhas de Inga capitata Benth. O dossel foi acessado utilizando uma torre de observação localizada na Reserva ZF2 do INPA $\left(02^{\circ} 35^{\prime} 21^{\prime \prime} \mathrm{S}, 60^{\circ} 06^{\prime} 53^{\prime \prime} \mathrm{W}\right)$. Dados coletados (Li-6400, Li-Cor, EUA) em [CO $\left.\mathrm{CO}_{2}\right]$ de 380 ppm e radiação fotossinteticamente ativa (PAR) de $500 \mu \mathrm{mol} \mathrm{m}^{-2} \mathrm{~s}^{-1}$ ) na câmera foliar. Dados originais não publicados. 
excedem um ponto máximo, observa-se a resposta clássica de diminuição de $g_{\mathrm{s}}$ com aumento no DPV. Conforme mostrado na Figura 7, quando o DPV é inferior a $1,6 \mathrm{kPa}$ e a temperatura inferior a $32^{\circ} \mathrm{C}, g_{\mathrm{s}}$ aumenta com temperatura.

Ao longo do dia, além da luminosidade, o potencial hídrico e a variação no DPV (Monteith, 1995; Singsaas et al., 2000; Iio et al., 2004) são fatores que mais influenciam nos valores da fotossíntese. Tanto em arvoretas como em árvores de dossel outro fator que pode influenciar a fotossíntese é de caráter endógeno, associado ao funcionamento de relógio biológico (Doughty et al., 2006). Mendes \& Marenco (2014) observaram que no seu ambiente natural, folhas de arvoretas iluminadas artificialmente iniciam o processo de abertura de estôma- tos antes do amanhecer evidenciando a participação de um relógio biológico no funcionamento estomático.

A fotossíntese responde rapidamente à variação na irradiância até atingir o ponto de saturação $\left(P_{\mathrm{S}}\right)$, o qual normalmente ocorre em irradiâncias de $500 \mu \mathrm{mol} \mathrm{m}{ }^{-2}$ $\mathrm{s}^{-1}$ (Figura 1, folha de sombra) a $1000 \mu \mathrm{mol} \mathrm{m} \mathrm{m}^{-2} \mathrm{~s}^{-1} \mathrm{em}$ folhas de sol (Marenco et al., 2001). O $P_{\mathrm{S}}$ do ecossistema florestal está acima de $1200 \mu \mathrm{mol} \mathrm{m} \mathrm{m}^{-2} \mathrm{~s}^{-1}$ (Malhi et al., 1998). Esse aumento (com relação à folha individual) ocorre pela redução de radiação devido ao auto sombreamento da folhagem no dossel das árvores. $\mathrm{O}$ ecossistema também apresenta ponto de compensação $\left(P_{\mathrm{C}}\right)$ bem maior do que aquele observado em nível de folha, $170 \mu \mathrm{mol} \mathrm{m} \mathrm{m}^{-2} \mathrm{~s}^{-1}$ (irradiância incidente no topo da floresta) para o ecossistema (Malhi et al., 1998)

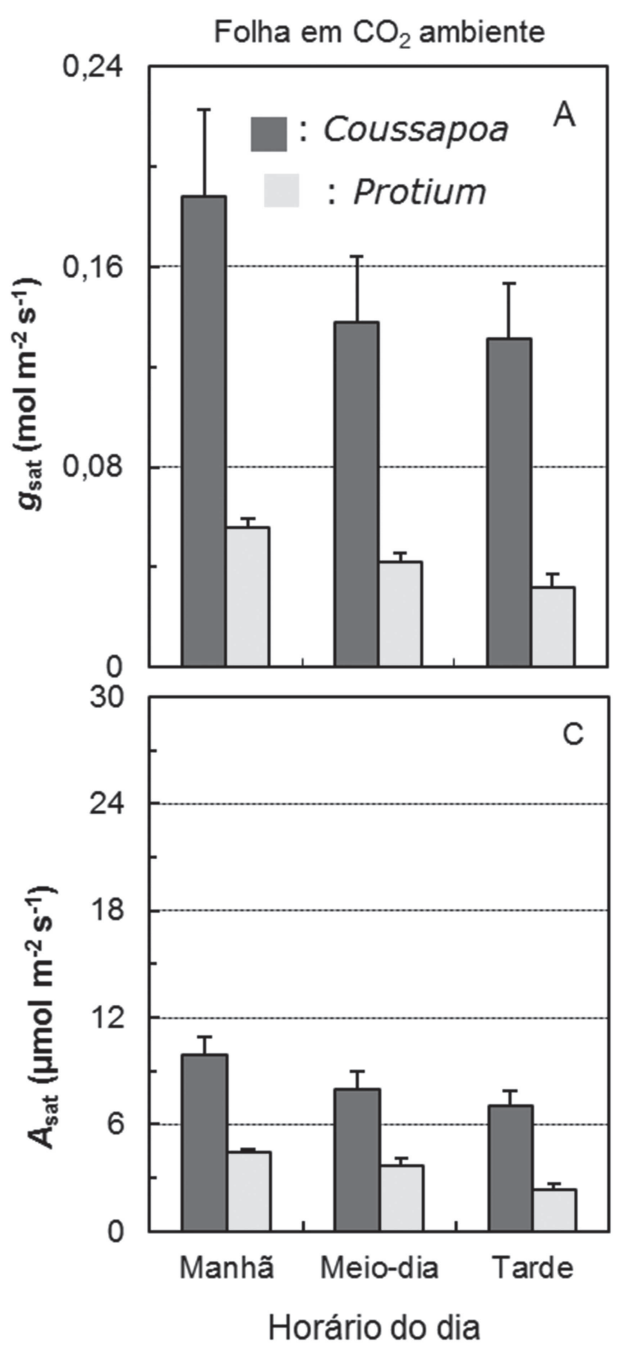

Folha em $\mathrm{CO}_{2}$ elevado $(2000 \mathrm{ppm})$

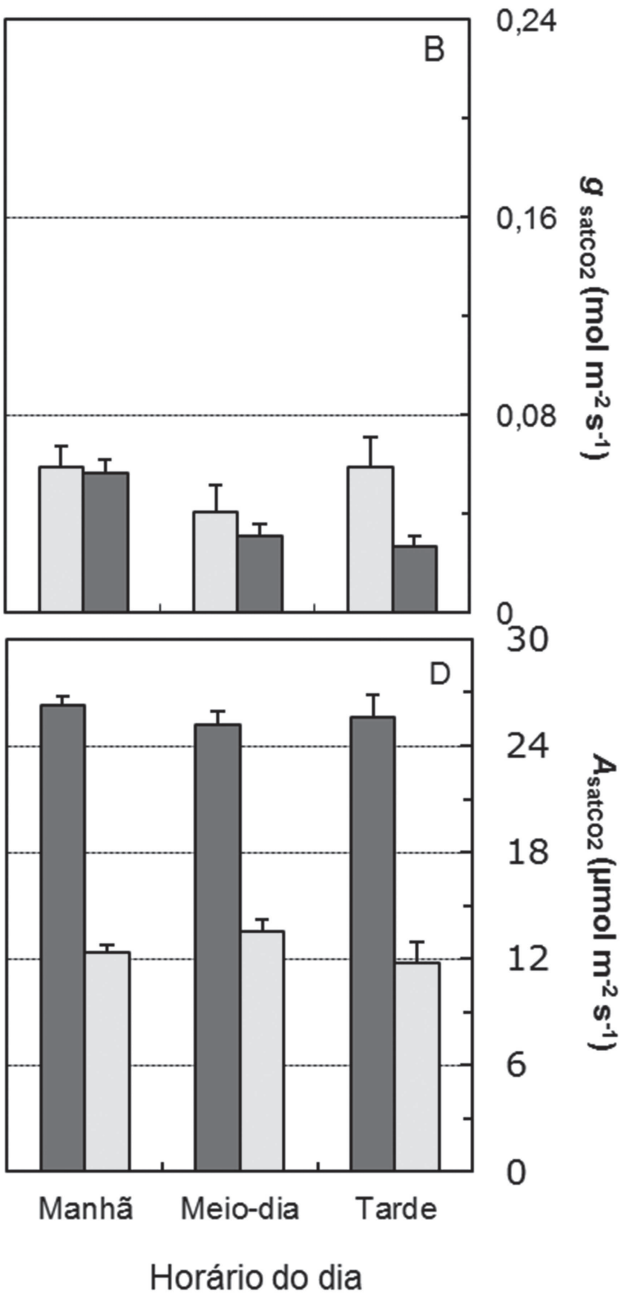

Figura 5. Variação da fotossíntese $(A)$ e condutância estomática $\left(g_{\mathrm{s}}\right)$ em condições de luz saturante $\left(A_{\mathrm{sat}} g_{\mathrm{sat}}\right)$ e em elevada $\left[\mathrm{CO}_{2}\right]$ na câmera foliar $\left(A_{\mathrm{SatCO} 2}, g_{\mathrm{satCO} 2}\right)$ nos períodos da manhã (08:00-11:00), meio dia (11:01-13:00 e tarde (13:01-16:00) em folhas de Coussapoa orthoneura e Protium opacum. O dossel foi acessado utilizando uma torre de observação localizada na Reserva ZF2 do INPA (02 ${ }^{\circ}$ 35’21" S, 60 06’ 53" W). Painel A,C em [CO $]$ ambiente, 380 ppm; painel B,D em elevada $\left[\mathrm{CO}_{2}\right]$ na câmera foliar, 2000 ppm. Dados coletados utilizando medidor de fotossíntese (Li-6400, Li-Cor, EUA). Condições experimentais conforme descrito por Marenco et al. (2007). Note que em alta $\left[\mathrm{CO}_{2}\right]$ a fotossíntese mostra pouca variação ao longo do dia, mostrando que a redução observada em $A$ (manhã vs tarde) em $\left[\mathrm{CO}_{2}\right]$ ambiente deve-se a redução em $g_{s}$. Dados originais não publicados. 
contra 20 a $50 \mu \mathrm{mol} \mathrm{m} \mathrm{m}^{-2} \mathrm{~s}^{-1}$ observado em folha individual (Marenco et al., 2001). De fato, valores de $P_{\mathrm{C}}$ inferiores a $20 \mu \mathrm{mol} \mathrm{m} \mathrm{m}^{-2} \mathrm{~s}^{-1}$ podem ser encontrados em plantas que crescem no sub-bosque da floresta (Mendes \& Marenco, 2014). Embora aumentos artificiais na irradiância disponível no dossel possam favorecer a fotossíntese (Graham et al., 2003), Malhi et al. (1998) não observaram aumentos na fotossíntese em decorrência da maior irradiância que ocorre na época seca na Amazônia central. Tanto em nível de folha (Marenco et al., 2014) como em nível de ecossistema, a fixação de $\mathrm{CO}_{2}$ segue um padrão diurno (Malhi et al., 1998). Em condição de alta irradiância a fixação de $\mathrm{CO}_{2}$ do ecossistema varia entre 16 e $25 \mu \mathrm{mol} \mathrm{m}{ }^{-2} \mathrm{~s}^{-1}$ (Malhi et al., 1998; Goulden et al., 2004). Além da irradiância, outros fatores que influenciam no padrão diurno da fotossíntese e condutância dos estômatos incluem variações diurnas no potencial hídrico $(\Psi)$ da folha (Costa \& Marenco, 2007; Camargo \& Marenco, 2012), temperatura (Tribuzy, 2005) e DPV (Figura 7).

\section{Fotorrespiração}

As plantas do tipo $\mathrm{C}_{3}$ (e.g. árvores da Amazônia) apresentam o fenômeno da fotorrespiração, processo que ocorre devido a Rubisco (enzima de carboxilação) também ter a capacidade de utilizar oxigênio como substrato. Desta forma a intensidade da fotorrespiração está relacionada à disponibilidade de oxigênio nos cloroplastos.

$\mathrm{O}$ aumento da temperatura eleva a relação $\mathrm{O}_{2} / \mathrm{CO}_{2}$ dissolvido no cloroplasto, com isso aumenta a fotorrespiração. Por outro lado, a temperatura também influencia

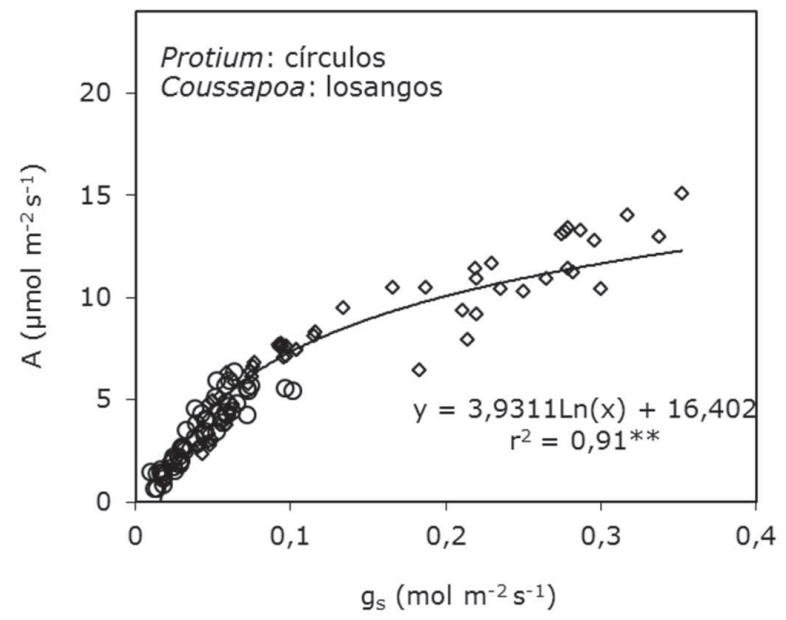

Figura 6. Relação entre fotossíntese $(A)$ e condutância estomática $\left(g_{\mathrm{s}}\right)$ em folhas de Coussapoa orthoneura Standley (Cecropiaceae) e Protium opacum Swart (Burseraceae). O dossel (22 a $27 \mathrm{~m}$ ) foi acessado utilizando uma torre de observação localizada na Reserva ZF2 do INPA $\left(02^{\circ} 35^{\prime} 21^{\prime \prime} \mathrm{S}, 60^{\circ} 06^{\prime} 53^{\prime \prime}\right.$ W). Dados coletados em $\left[\mathrm{CO}_{2}\right]$ de $380 \mathrm{ppm}$ e radiação fotossinteticamente ativa (PAR de $500 \mu \mathrm{mol} \mathrm{m}^{-2} \mathrm{~s}^{-1}$ ) na câmera foliar. Dados coletados utilizando medidor de fotossíntese (Li-6400, Li-Cor, EUA). Dados originais não publicados. o fator de especificidade da Rubisco, $\tau$ (tau). A especificidade da Rubisco está definida pela equação (Brooks \& Farquhar, 1985):

$\tau=V_{\mathrm{c}} K_{\mathrm{o}} / K_{\mathrm{c}} V_{\mathrm{o}}$,

Em que, $V$ representa o $V_{\max }$ para carboxilação $\left(V_{\mathrm{c}}\right)$ e oxigenação $\left(V_{\mathrm{o}}\right)$ e $K$ denota o $K_{\mathrm{m}}$ para carboxilação $\left(K_{\mathrm{c}}\right)$ e oxigenação $\left(K_{\mathrm{o}}\right)$. A afinidade da Rubisco pelo $\mathrm{CO}_{2}$ é muito maior $\left(K_{\mathrm{m}}\right.$ de 10 a $\left.20 \mu \mathrm{M}\right)$ do que a sua afinidade pelo $\mathrm{O}_{2}\left(K_{\mathrm{m}}\right.$ de 400 a $600 \mu \mathrm{M}$; Jensen, 1990), mas como a concentração de oxigênio $\left[\mathrm{O}_{2}\right]$ na atmosfera é muito superior à concentração de $\mathrm{CO}_{2}$ (i.e. $21,8 \%$ versus $0,04 \%$ ), a fixação de $\mathrm{O}_{2}$ nas plantas $\mathrm{C}_{3}$ é expressiva. Estima-se que a redução na relação $\mathrm{CO}_{2} / \mathrm{O}_{2}$ nos cloroplastos seja responsável por um terço do aumento na fotorrespiração em altas temperaturas. Isto é, $66 \%$ das perdas de $\mathrm{CO}_{2}$ associadas à fotorrespiração derivam da redução no fator de especificidade da Rubisco (Von Caemmerer \& Quick, 2000). Em Minquartia guianensis, o rendimento

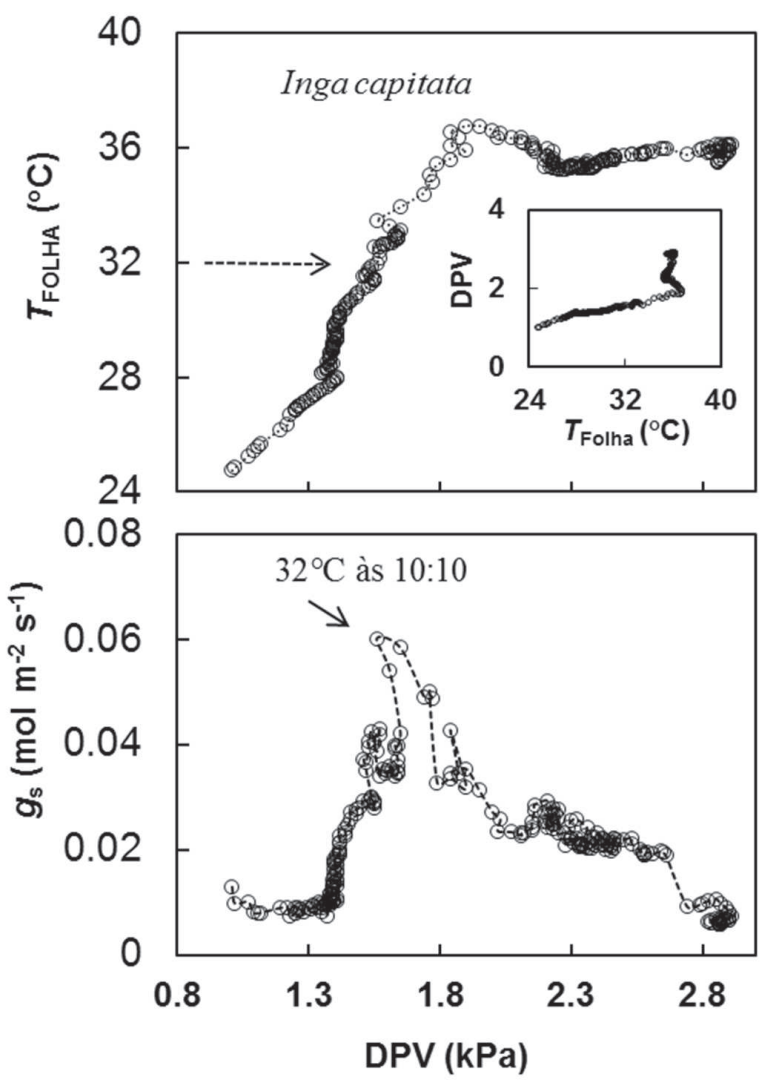

Figura 7. Temperatura da folha $\left(T_{\mathrm{FOLHA}}\right)$ e condutância estomática $\left(g_{\mathrm{s}}\right)$ em função da diferença de pressão de vapor folha-ar (DPV) em folhas de Inga capitata Benth. Observe $g_{\mathrm{s}}$ aumenta com aumento do DPV até $32^{\circ} \mathrm{C}$ (às 10:10 am), daí em diante, $g_{\mathrm{s}}$ declina com aumento no DPV. Note que quando $T_{\text {FOLHA }}$ atinge $36^{\circ} \mathrm{Co}$ DPV aumenta rapidamente (destaque no painel superior). Dados coletados de uma torre de observação a altura de $10 \mathrm{~m}$ do solo (irradiância de $500 \mu \mathrm{mol} \mathrm{m} \mathrm{s}^{-1}$ e 380 ppm de $\mathrm{CO}_{2}$ ), utilizando um medidor de fotossíntese (Li-6400, Li-Cor, EUA). Dados originais não publicados. 
quântico aparente $\left(\Phi_{\mathrm{r}}\right)$ determinado à temperatura de $26^{\circ} \mathrm{C}$ é $25 \%$ menor em ar ambiente do que em atmosfera com $1 \%$ de $\mathrm{O}_{2}$, diminuindo em ar ambiente os valores de $\Phi_{\mathrm{I}}$ conforme a temperatura aumenta (Figura 2). Em comparação com mensurações feitas em $\mathrm{CO}_{2}$ ambiente, a fotossíntese pode duplicar quando efetuada em atmosfera enriquecida com $\mathrm{CO}_{2}$ (Figura 1). De forma geral, estima-se que em temperaturas amenas $\left(\sim 25^{\circ} \mathrm{C}\right)$ aproximadamente $25 \%$ do carbono fixado pela fotossíntese é perdido via fotorrespiração (Marenco \& Lopes, 2009).

A taxa máxima de transporte de elétrons $\left(J_{\max }\right)$ e $V_{\text {cmax }}$ (valores padronizados a $25^{\circ} \mathrm{C}$ ) variam consideravelmente entre espécies. $V_{\text {cmax }}$ varia na faixa de 10 a $75 \mu \mathrm{mol} \mathrm{m}$ ${ }^{2} \mathrm{~s}^{-1}$ (Domingues et al., 2014; Magalhães et al., 2014) e $J_{\max }$ varia entre e 40 e $112 \mu \mathrm{mol} \mathrm{m} \mathrm{m}^{-2} \mathrm{~s}^{-1}$ (Domingues et al., 2007; Magalhães et al., 2014), estando ambos parâmetros altamente correlacionados. A relação $J_{\max } /$ $V_{\text {cmax }}$ varia de 1 a 1,67 (Medlyn et al., 2002).

\section{Concentração de $\mathrm{CO}_{2}$}

A enzima Rubisco pode atuar em duas modalidades: oxigenase (fixando $\mathrm{O}_{2}$ e induzindo a produção de $\mathrm{CO}_{2}$ fotorrespiratório) e carboxilase (fixando $\mathrm{CO}_{2}$ na fotossíntese). Em experimentos de curto prazo, aumento na concentração de $\mathrm{CO}_{2}$ causa aumento na temperatura ótima da fotossíntese (Figura 8). Isso ocorre porque em baixa concentração de $\mathrm{CO}_{2}$ a função oxigenase da Rubisco predomina em relação à função carboxilase e nessa condição (papel oxigenase) à proporção que a temperatura aumenta a produção de $\mathrm{CO}_{2}$ fotorrespiratório aumenta mais rapidamente do que a carboxilação. Já em alta concentração de $\mathrm{CO}_{2}$, a função carboxilase predomina e aumenta com a temperatura até o ponto em que a

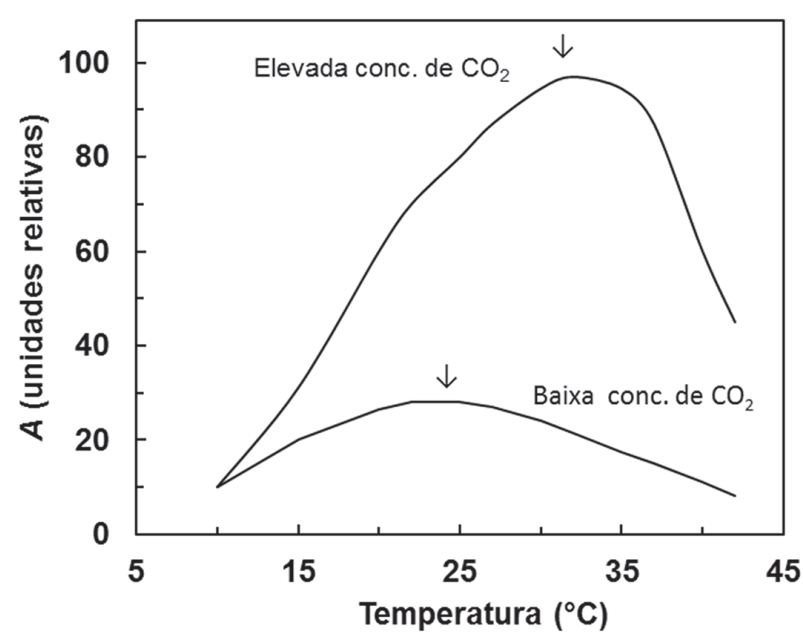

Figura 8. Ilustração esquematizada da fotossíntese em função da temperatura em baixa e elevada concentração de $\mathrm{CO}_{2}$. A seta vertical indica o ponto de temperatura ótima da fotossíntese. Adaptado de Marenco \& Lopes (2009). carboxilação é limitada pela taxa máxima de transporte de elétrons, $J_{\max }$ (Farquhar et al., 1980).

Em experimento de longo prazo, entretanto, a exposição continuada à atmosfera enriquecida com $\mathrm{CO}_{2}$ pode levar a aclimatação da fotossíntese (Marenco \& Lopes, 2009). Como resultado, quando a fotossíntese é mensurada em alta concentração de $\mathrm{CO}_{2}$ (e.g. 700 ppm), plantas mantidas em atmosfera enriquecida apresentam taxas menores de fotossíntese do que aquelas mantidas em concentração ambiente de $\mathrm{CO}_{2}$ (e.g. 380- 400 ppm).

Nowak et al. (2004) analisaram os resultados de 16 experimentos de longo prazo, representativos de vários tipos de vegetação no que se refere à resposta ao enriquecimento com $\mathrm{CO}_{2}$. Eles relatam que na atmosfera enriquecida com $\mathrm{CO}_{2}$ a fotossíntese foi $26 \%$ maior do que no controle (i.e. plantas em $\mathrm{CO}_{2}$ ambiente). Porém, eles também notaram que a resposta positiva da fotossíntese ao enriquecimento de $\mathrm{CO}_{2}$ estava associada ao aumento do teor de nitrogênio da folha. Isto mostra a necessidade de se conduzir mais pesquisas para poder se estimar com precisão qual o efeito real do enriquecimento com $\mathrm{CO}_{2}$ na assimilação de carbono de árvores da Amazônia.

Desconsiderando eventual aclimatação da fotossíntese à atmosfera enriquecida com $\mathrm{CO}_{2}$, estimativas feitas utilizando técnicas de modelagem preveem que à proporção que a concentração de $\mathrm{CO}_{2}$ do ar aumenta ocorrerá também um aumento nas taxas de fotossíntese, pelo menos até 2050 (Lloyd \& Farquhar, 2008).

Para ecossistemas terrestres no seu conjunto, o modelo HadCM3LC (que leva em conta efeitos conjuntos da atmosfera, biosfera e oceanos nas previsões, i.e. modelo acoplado) prognostica ganhos de carbono nos ecossistemas terrestres até o ano 2030, a partir daí poderá ocorrer declínio constante até valores negativos (6 gigatoneladas, Gt de carbono por ano) em 2100; outros modelos (e.g. LLNL) prognosticam ganhos constantes até um valor de $10 \mathrm{Gt}$ (Carbono) ano-1, em 2100 (Friedlingstein et al., 2006).

No que se refere especificamente a florestas úmidas tropicais, modelos matemáticos têm mostrado que nesses ecossistemas a produtividade primária bruta $\left(A_{\mathrm{B}}\right)$ aumentou de 1,94 $\mathrm{kg}(\mathrm{C}) \mathrm{m}^{-2}$ ano $^{-1}$ em 1730 (Lloyd \& Farquhar, 1996) para 2,49 $\mathrm{kg}(\mathrm{C}) \mathrm{m}^{-2} \mathrm{ano}^{-1}$ no ano $2000 \mathrm{e}$ estima-se que aumente para $3,25 \mathrm{~kg}(\mathrm{C}) \mathrm{m}^{-2} \mathrm{ano}^{-1} \mathrm{em} 2040$ (Lloyd \& Farquhar, 2008), assumindo $39,7^{\circ} \mathrm{C}$ e $550 \mathrm{ppm}$ de $\mathrm{CO}_{2}$ em 2040.

Malhi et al. (1998) estimaram que na Amazônia central, a produtividade primária bruta $A_{\mathrm{B}}$ [o somatório da respiração $(2,45)$ e das trocas líquidas do ecossistema $(0,59)$ ] foi de $3,04 \mathrm{~kg}(\mathrm{C}) \mathrm{m}^{-2} \mathrm{ano}^{-1}$, um pouco acima dos valores estimados por Lloyd \& Farquhar (2008) para florestas úmidas tropicais. 
Lewis et al. (2009) concluíram que na Amazônia houve ganhos na biomassa de árvores entre 1975 e 2005 e atribuíram esses ganhos de carbono ao aumento na concentração de $\mathrm{CO}_{2}$ e em segundo lugar ao aumento da radiação solar. Embora os prognósticos estimem que a fotossíntese aumente com aumento na concentração de $\mathrm{CO}_{2}$, a relação $\mathrm{C}_{\mathrm{i}} / \mathrm{C}_{\mathrm{a}}\left(\mathrm{CO}_{2}\right.$ nos espaços intercelulares $/ \mathrm{CO}_{2}$ no ar $)$ deve permanecer constante, devido ao aumento na taxa de fotossíntese ocorrer sem alteração na condutância estomática (Bonal et al., 2011). Prognósticos de modelagem (e.g. Friedlingstein et al., 2006) são consistentes com observações feitas em parcelas experimentais da Amazônia nas quais tem sido observado que a biomassa da parte aérea (árvores acima de $10 \mathrm{~cm}$ de diâmetro) tem aumentado entre 100 e $122 \mathrm{~g} \mathrm{~m}^{-2}$ ano $^{-1}$ (Baker et al., 2004).

\section{Temperatura}

Estima-se que nas últimas décadas as florestas tropicais tiveram incrementos aumentos na temperatura de $0,026^{\circ} \mathrm{C}$ por ano e aumento anual de $1,66 \mathrm{ppm}$ na concentração de $\mathrm{CO}_{2}$ (Lewis et al., 2009). A temperatura afeta a atividade de enzimas da fotossíntese e a cadeia do transporte de elétrons (Sage \& Kubien, 2007). Aumentos na temperatura aumentam tanto a fotorrespiração como a diferença de pressão vapor (DPV). A fotorrespiração tem efeito direto e o DPV efeito indireto na fotossíntese via o seu efeito no fechamento dos estômatos (Doughty \& Goulden, 2008; Marenco \& Lopes, 2009). Por outro lado, aumento na temperatura causa aumento na atividade da Rubisco em torno de $45^{\circ} \mathrm{C}$, que é muito maior do que a temperatura máxima para o transporte de elétrons, em torno de $35-37^{\circ} \mathrm{C}$ (Cen \& Sage, 2005; Lloyd \& Farquhar, 2008). Devido ao efeito da temperatura na fotorrespiração, o ótimo da temperatura aumenta em plantas expostas à atmosfera enriquecida com $\mathrm{CO}_{2}$ (Figura 8).

Plantas de diversas espécies tem mostrado capacidade de aclimatação à temperatura observada durante o crescimento (Berry \& Bjorkman, 1980). A aclimatação à baixa temperatura envolve mecanismos diferentes daqueles requeridos para aclimatação à altas temperaturas. A aclimatação à baixa temperatura envolve (1) aumento no conteúdo de enzimas da fotossíntese. Por exemplo, aumento no conteúdo de Rubisco (por unidade de área) e de componentes do transporte de elétrons; (2) síntese de formas da Rubisco tolerantes ao frio e (3) síntese de componentes de membrana que permitam a manutenção de fluidez em baixas temperaturas.

A aclimatação a altas temperaturas envolve (1) mecanismos que aumentam a capacidade do transporte de elétrons; (2) a síntese de formas da Rubisco ativase (enzima necessária para a ativação da Rubisco) tolerantes ao calor e (3) a diminuição na respiração (Yamori $e t$ al., 2014). Um dos principais efeitos de altas temperaturas é o vazamento de prótons através da membrana, o que desacopla a síntese de ATP do transporte de elétrons. Por isso, o aumento da estabilidade da membrana é condição essencial para a aclimatação à alta temperatura. No geral, a ativação da Rubisco diminui em altas temperaturas. A síntese de isoformas da Rubisco ativase com maior estabilidade térmica contribui para a aclimatação da Rubisco a altas temperaturas $\left(35-40^{\circ} \mathrm{C}\right)$. Além disso, síntese de proteínas estabilizadoras de baixo peso molecular (chaperonas) também contribuem para aclimatação a altas temperatura (Yamori et al., 2014).

\section{RELAÇÕES HÍDRICAS}

A disponibilidade de água é um dos fatores que mais influencia a fotossíntese e o crescimento das plantas. $\mathrm{O}$ estresse hídrico prolongado acelera a taxa de degradação da clorofila (Mafakheri et al., 2010) e eventualmente estimula a senescência precoce de folhas. Porém, o efeito imediato do estresse hídrico é causar o fechamento dos estômatos (Loreto et al., 2003) e redução na condutância do mesofilo (Flexas et al., 2012). O fechamento dos estômatos leva a redução na fotossíntese. Em função disso há relação estreita entre condutância estomática e fotossíntese (Figura 6). Evidentemente, à proporção que o estresse hídrico aumenta a limitação da fotossíntese causada por fatores não estomáticos associados ao metabolismo fotossintético torna-se mais evidente (Martin \& Ruiz-Torres, 1992). Em condições de estresse hídrico tem-se observado tanto redução na atividade da Rubisco (Parry et al., 2002) como redução na atividade da redutase do nitrato. $\mathrm{O}$ papel preponderante da limitação estomática associada ao estresse hídrico na fotossíntese tem sido demonstrado ao se eliminar a barreira imposta pelos estômatos. Por exemplo, ao se retirar a epiderme da folha de forma que o $\mathrm{CO}_{2}$ possa penetrar livremente nas cavidades subestomáticas (Schwab et al., 1989). Outra abordagem utilizada pressupõe que o aumento da concentração de $\mathrm{CO}_{2}$ no entorno da folha pode compensar a redução na abertura dos estômatos (Kaiser, 1987; Tourneux \& Peltier, 1995).

Em extensas áreas da Amazônia ao longo do ano ocorrem variações nos teores de umidade do solo, as quais são mais pronunciadas nas partes da bacia amazônica com estação seca definida. A diminuição da umidade do solo causa redução nas taxas de fotossíntese do ecossistema florestal na época seca (Malhi et al., 1998). Em comparação com a época chuvosa, os estômatos tendem a permanecer menos tempo aberto na época seca, como resultado, a fotossíntese diária total é menor na época seca do que na chuvosa. Quando experimentalmente a concentração de $\mathrm{CO}_{2}$ é aumentada no entorno da folha, a 
restrição na fotossíntese imposta pela redução em $g_{\mathrm{s}}$ pode ser superada, conforme mostrado na Figura 5, o que indica que a redução observada na fotossíntese na época seca (Malhi et al., 1998) provavelmente deve-se a redução em $g_{s}$. Dependendo do ano, na Amazônia central a umidade pode variar de $48 \%$ (v/v, época seca) a $56 \%$ (v/v) no período chuvoso (Marenco et al., 2014). Quando as variações na umidade do solo são de pouca magnitude as taxas de fotossíntese e a condutância estomática de arvoretas (crescendo no sub-bosque) não mostram diferenças entre as épocas seca e chuvosa (Mendes \& Marenco, 2010; Magalhães et al., 2014). Valores de fotossíntese saturada por luz (em nível de folha) podem oscilar entre 2 e $15 \mu \mathrm{mol} \mathrm{m} \mathrm{m}^{-2} \mathrm{~s}^{-1} \mathrm{e}$ a condutância estomática (em luz saturante ) de 0,03 a $0,3 \mathrm{~mol} \mathrm{~m}^{-2} \mathrm{~s}^{-1}$ (Mendes \& Marenco 2010; Domingues et al., 2014). Estudo mais recente também confirma que em ano mais seco as variações nos teores de umidade do solo entre as épocas secas e chuvosa causam diferenças nas taxas de assimilação de carbono (Gatti et al., 2014).

O potencial hídrico da folha não permanece constante ao longo do dia (Costa \& Marenco, 2007) como poder ser ilustrado na Figura 9. Isso ocorre porque a taxa de transpiração da folha é maior do que a capacidade de absorção (raízes) ou maior do que a capacidade de transporte ao longo do tronco e galhos da árvore. O fluxo de seiva aumenta ao amanhecer seguindo o efeito da irradiância na abertura dos estômatos (Figura 10). Após atingir um máximo ao meio dia, o fluxo de seiva diminui em paralelo com a diminuição do déficit de pressão de vapor do ar, DPV ${ }_{\text {ar }}$ (Figura 11, a partir do meio dia). Observe nessa figura que dias com maior radiação (Figura 10, dias 118-119) tiveram os maiores valores de fluxo noturno (400 a $750 \mathrm{~mL} \mathrm{hr}^{-1}$ ). Já no dia nublado observou-se fluxo decrescente durante o dia todo até estabili-

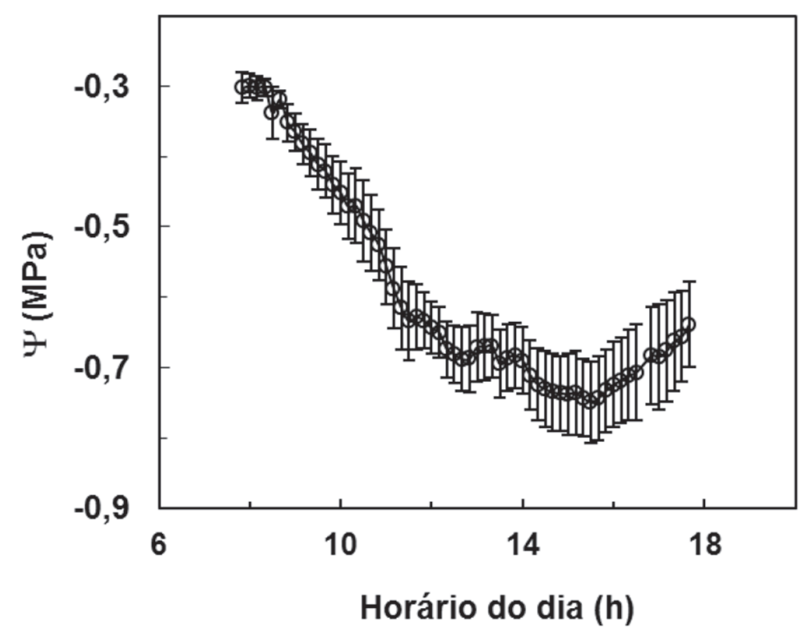

Figura 9. Variação do potencial hídrico da folha $(\Psi)$ em Carapa guianensis em função do horário do dia. Fonte: Costa \& Marenco (2007). zar em $150 \mathrm{~mL} \mathrm{~h}^{-1}$ após a meia noite do dia seguinte (Figura 11). Os picos de fluxos máximos relatados para Ceiba pentandra são menores do que aqueles observados em outras espécies tropicais de diâmetros similares (Goldstein et al., 1998), mas a transpiração total ( 40 litros de água por dia registrado em C. pentandra) está dentro da faixa de valores observados por Cienciala et al. (2000) em plantações de Acacia mangium. De fato, a variabilidade do fluxo mostra o efeito de condições ambientais, sobretudo no que se refere ao $\mathrm{DPV}_{\mathrm{ar}}$. Fluxo noturno ascendente pode indicar duas coisas: (1) transpiração noturna ou (2) fluxo de seiva para recarga da água dos tecidos e estruturas de armazenamento de
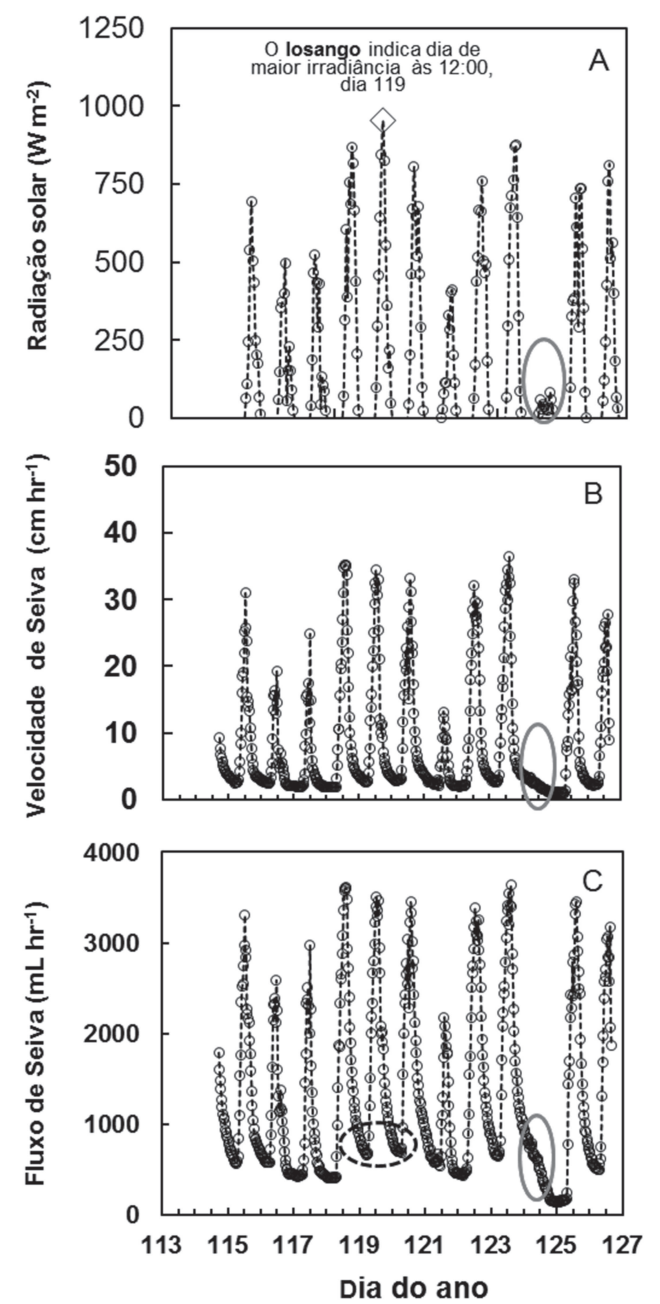

Figura 10. Variação da diurna da radiação solar (A), velocidade da seiva (B) e fluxo de seiva (C) em uma árvore de Ceiba pentandra de $20 \mathrm{~cm}$ de diâmetro. Dados coletados no Campus do INPA-V8 entre 24 de abril e 06 de maio de 2014. O círculo em linha contínua mostra um dia de baixa radiação solar (dia 124) e fluxo diurno decrescente. $\mathrm{O}$ círculo em linha tracejada nos dias 119 e 120 (de alta radiação solar) mostram o fluxo noturno de 800 a $1000 \mathrm{~mL} \mathrm{hr}^{-1}$. Painel B e C: dados coletados utilizando um medidor de fluxo (SFM1, ICT International, Austrália). Dados não publicados. Os dados de radiação solar foram obtidos do INMET (2014). 
água, principalmente no tronco e galhos grossos da árvore. A transpiração noturna tem sido relatada em várias espécies (Dawson et al., 2007; Kavanagh et al., 2007; Marks \& Lechowicz, 2007; Forster, 2014) e está principalmente relacionada ao déficit de pressão de vapor, $\mathrm{DPV}_{\text {ar }}$ (Zeppel et al., 2010; Fisher et al., 2007). Por isso, se os estômatos não estão perdendo água, como normalmente ocorre quando o $\mathrm{DPV}_{\mathrm{ar}}$ é nulo (assumindo que a folha e o ar tem a mesma temperatura), o fluxo de seiva noturno está essencialmente direcionado para a recarga das estruturas de armazenamento (recarga da capacitância), assumindo participação nula do fenômeno de gutação em árvores. Conquanto, tanto a recarga da capacitância como a transpiração atuam como forças motrizes do fluxo noturno quando a atmosfera está insaturada com vapor de água (umidade do ar $<100 \%$ ).

Gatti et al. (2014) estudaram o balanço de carbono em um ano seco (2010) e outro chuvoso (2011) para a bacia amazônica $\left(6,77 \times 10^{6} \mathrm{~km}^{2}\right)$. Estes autores concluíram que no ano seco a Amazônia mostra balanço neu-
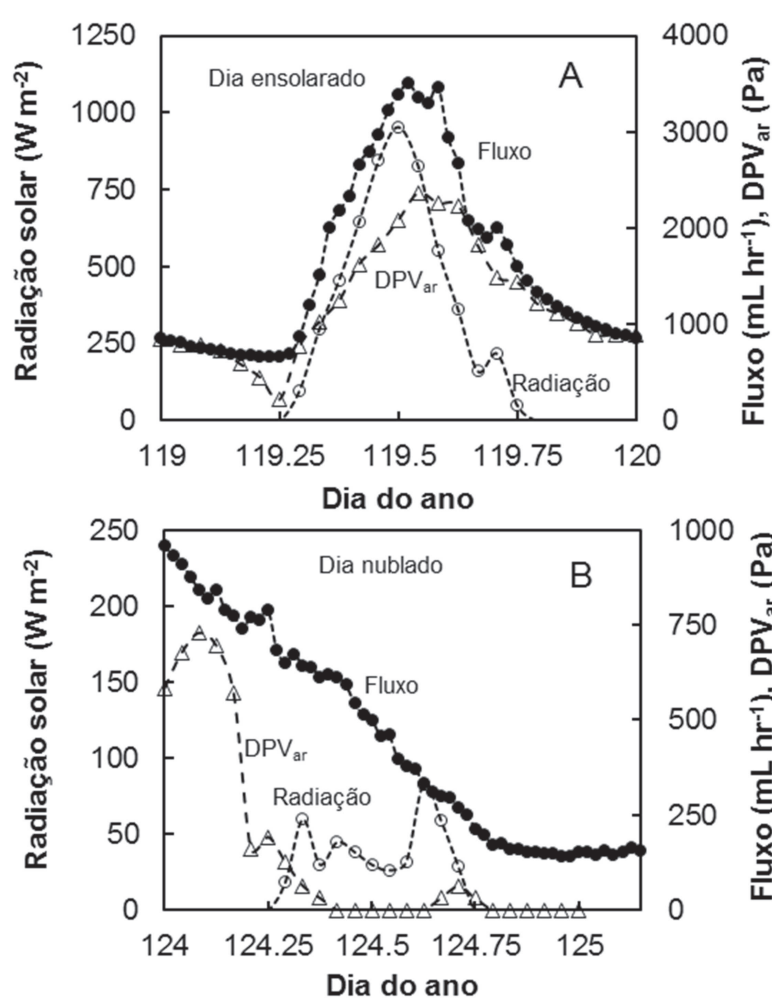

Figura 11. Variação da diurna da radiação solar (o: círculo vazio), déficit de pressão de vapor do ar ( $\mathrm{DPV}_{\mathrm{ar}}, \Delta$ : triângulo vazio) e fluxo de seiva (0: circulo cheio) em Ceiba pentandra em dias de alta (painel A, dia 119, fluxo total de $40 \mathrm{~L} \mathrm{dia}^{-1}$ ) e baixa radiação solar (painel B, dia 124). Dados coletados conforme descrito na Figura 10. No painel B, a linha tracejada mostra o $\mathrm{DPV}_{\mathrm{ar}}$ Observe $^{\circ}$ que no dia 124 o fluxo foi decrescente até estabilizar em $150 \mathrm{~mL}$ $\mathrm{hr}^{-1}$ (velocidade de $1 \mathrm{~cm} \mathrm{hr}^{-1}$ ) após a meia noite do dia seguinte. Dados originais não publicados. $\mathrm{O}$ dados de radiação solar, temperatura e umidade para o cálculo do déficit de pressão de vapor do ar $\left(\mathrm{DPV}_{\mathrm{ar}}\right)$ foram obtidos do INMET (2014). tro (sem perda nem ganho), devido à redução da fotossíntese por causa da falta de água. Já no ano chuvoso (2011) houve acúmulo de carbono $[0.25 \operatorname{Pg}(\mathrm{C})$ ano $^{-1}$, o que é consistente com estimativas de longo prazo, que indicam que a Amazônia atuará como sumidouro de carbono. Por outro lado, quando as perdas de $\mathrm{CO}_{2}$ devido ao efeito das queimadas foram levadas em consideração, no ano seco houve balanço negativo e no ano chuvoso, os ganhos de carbono da fotossíntese apenas compensaram as perdas de carbono devido às queimadas (Gatti et al., 2014).

$\mathrm{Na}$ Amazônia central a fotossíntese do ecossistema mostra variação diurna com picos de fotossíntese do ecossistema ocorrendo entre 10:00 e 12:00 e variando de $10 \mu \mathrm{mol} \mathrm{m} \mathrm{m}^{-2} \mathrm{~s}^{-1}$ na época seca para $20-25 \mu \mathrm{mol} \mathrm{m} \mathrm{s}^{-2}$ na época chuvosa (Malhi et al., 1998). Estes autores atribuíram as diferenças sazonais à variação na umidade do solo e as diurnas à variação na irradiância e no $\mathrm{DPV}_{\mathrm{ar}}$.

\section{RESPIRAÇÃO}

A respiração é um processo essencial para a manutenção dos processos celulares e crescimento do vegetal (Marenco \& Lopes, 2009). Devido aos efeitos da fotossíntese na respiração, a respiração da folha que ocorre durante o dia $\left(R_{\mathrm{d}}\right)$ é menor do que a respiração noturna, $R_{\mathrm{N}}$ (Brook \& Farquhar, 1985). O valor de $R_{\mathrm{N}}$ da folha é obtido como o valor absoluto da fotossíntese de folha no escuro. Já o valor de $R_{\mathrm{d}}$ é obtido como o valor absoluto da fotossíntese de uma folha exposta a luz e em concentração de $\mathrm{CO}_{2}$ nos espaços intercelulares $\left(\mathrm{C}_{\mathrm{i}}\right)$ igual a $\Gamma^{*}$. Em que, $\Gamma^{*}$ é definido como o "ponto de compensação por $\mathrm{CO}_{2}$ " na ausência de $R_{\mathrm{d}}$ (Brook \& Farquhar, 1985). Tanto $R_{\mathrm{d}}$ como $\Gamma^{*}$ variam com a temperatura, conforme mostrado na Figura 12.

A resposta da respiração à mudança da temperatura é diferente da observada para a fotossíntese. Enquanto a temperatura ótima da fotossíntese ocorre em geral entre 20 e $30^{\circ} \mathrm{C}$, a temperatura ótima da respiração ocorre a temperaturas relativamente altas (Figura 12), logo abaixo da temperatura de inativação pelo calor. Assim, quando a temperatura ultrapassa o ótimo para a fotossíntese, a fotossíntese declina, mas a respiração continua a aumentar. Por isso o processo de aclimatação a alta temperatura também envolve a aclimatação da respiração. Para uma determinada temperatura (e.g. $30^{\circ} \mathrm{C}$ ), folhas aclimatadas a altas temperaturas apresentam taxas menores de respiração do que folhas de ambientes mais frios (Atkin et al., 2005).

Em nível de ecossistema a produtividade primária liquida, $\mathrm{P}_{\mathrm{PL}}$ (crescimento novo) reflete o balanço entre fotossíntese bruta $\left(A_{\mathrm{B}}\right)$ e respiração total. Isto é:

$P_{\mathrm{PL}}=A_{\mathrm{B}}(1-R)$, 
Em que $R$ representa a proporção de carbono assimilado perdido via respiração total. A respiração $(R)$ inclui as perdas de carbono devido à respiração noturna do vegetal (folhas, raízes, etc.) e aquelas derivadas da emissão de compostos orgânicos voláteis, exsudação de compostos orgânicos e carboidratos liberados pela raiz (Lloyd \& Farquhar, 2008). No geral, estima-se que em florestas tropicais do total de carbono assimilado $\left(A_{\mathrm{B}}\right)$ entre 60 e $85 \%$ seja utilizado na respiração (Lloyd \& Faquhar, 2008). Para a Amazônia central a respiração total pode representar $80 \%$ de $A_{\text {в }}$ (Malhi et al., 1998).

\section{CRESCIMENTO DE ÁRVORES}

Dependo da região, as árvores da Amazônia podem apresentar maior aumento em diâmetro do tronco na
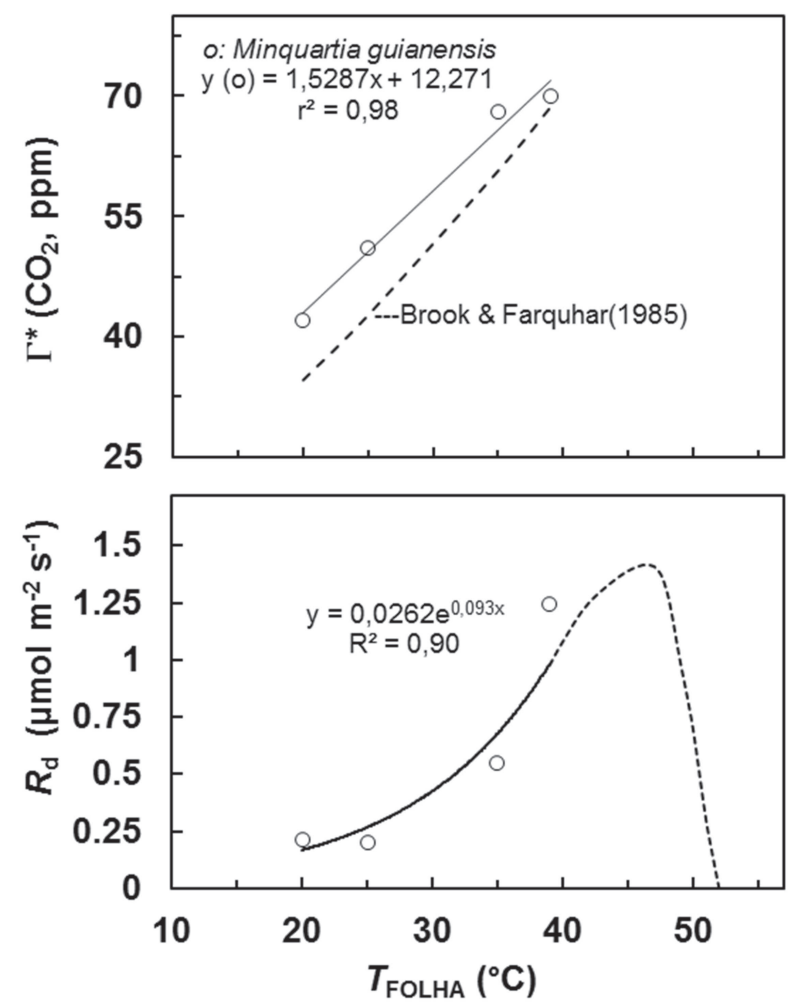

Figura 12. Ponto de compensação por $\mathrm{CO}_{2}(\Gamma)$ e respiração diurna $\left(\mathrm{R}_{\mathrm{d}}\right)$ em função da temperatura em folhas de Minquartia guianensis. $\Gamma^{*}$ corresponde ao "ponto de compensação" na ausência de $\mathrm{R}_{\mathrm{d}}$. No ponto de compensação por $\mathrm{CO}_{2}(\Gamma)$ a fotossíntese líquida é zero. Quando a concentração intercelular de $\mathrm{CO}_{2}$ atinge o valor $\Gamma^{*}$ a quantidade de $\mathrm{CO}_{2}$ fixado via fotossíntese é igual à quantidade de $\mathrm{CO}_{2}$ produzido via fotorrespiração. Por isso, em $\Gamma^{*} \mathrm{o} \mathrm{CO}_{2}$ liberado pela folha deve-se apenas à contribuição de $R_{d}$. Dados originais não publicados coletados utilizando um medidor de fotossíntese (Li-6400, Li-Cor, EUA) seguindo o protocolo de Brooks e Farquhar (1985). A linha tracejada no painel superior mostra os valores de $\Gamma^{*}$ calculados utilizando a equação de Brook e Farquhar (1985), sendo $\Gamma^{*}=42,7+1,68(\mathrm{~T}-25)+$ $\left.0,012(T-25)^{2} T \mathrm{em}^{\circ} \mathrm{C}\right)$. No painel inferior, a linha tracejada mostra a tendência esperada de $\mathrm{R}_{\mathrm{d}}$ assumindo queda brusca da respiração a partir de $47^{\circ} \mathrm{C}$ (Larcher, 1995). época chuvosa do que na época seca. Tem-se registrado maior crescimento na época chuvosa na Amazônia central (da Silva et al., 2002) e no sul da Amazônia (Grogan $\&$ Schulze, 2012). Porém, para outras localidades (e.g. centro leste) ainda não tem sido observada tendência definida (Wagner et al., 2014). Entretanto, contrário ao que tem sido observado em árvores adultas, para árvores na fase juvenil da Amazônia central não tem sido observado efeito da sazonalidade das chuvas no crescimento (Magalhães et al., 2014), provavelmente devido à menor perda de água em decorrência da proteção recebida do dossel da floresta. Também não se sabe se árvores adultas podem atuar como transportadores de água para as camadas mais superficiais do solo, o que favoreceria mudas e arvoretas do sub-bosque. Tem-se observado que árvores na fase juvenil (mudas e arvoretas) crescem mais rápido em ambientes menos sombreados (Mendes et al., 2013), com correlação positiva entre a taxa de crescimento das plantas e a fotossíntese (Magalhães et al., 2014).

\section{CONCLUSÕES}

$\mathrm{Na}$ época seca observa-se aumento da irradiância o que pode eventualmente favorecer a fotossíntese. Entretanto, a limitação imposta pela restrição hídrica na época seca leva a redução da fotossíntese sobretudo em árvores de dossel. Árvores em fase juvenil estão menos expostas às variações na umidade do ar o que permite que as taxas de fotossíntese oscilem menos ao longo do ano quando o período de seca é de curta duração. Em árvores da Amazônia a variação diurna da fotossíntese está relacionada à variação na irradiância, temperatura e déficit de pressão de vapor. Associado ao aumento da irradiância há também aumento da temperatura o que aumenta o déficit de pressão de vapor, isso favorece o fechamento dos estômatos nos horários da tarde. Em algumas espécies, a assimilação de carbono varia ao longo do dia em folhas mantidas em iluminação constante o que sugere o envolvimento de um relógio biológico, o qual pode ser diariamente ajustado de forma a acompanhar as variações diárias das variáveis do ambiente, principalmente as variações na irradiância. Diversos estudos mostram que na maior parte da Amazônia árvores com diâmetro (a 1,3 m do solo) acima de $10 \mathrm{~cm}$ crescem a taxas maiores na época chuvosa, sugerindo que o ecossistema florestal atua como sumidouro de carbono. Pela expressiva extensão territorial da Amazônia e diversidade de espécies da região, mais estudos ainda são necessários para determinar como fatores específicos do ambiente físico influenciam a assimilação de carbono e o crescimento de árvores nos diversos grupos funcionais. 


\section{AGRADECIMENTOS}

Ao MCTI-INPA, à Fundação de Amparo à Pesquisa do Estado do Amazonas (FAPEAM) pelo apoio à realização da pesquisa (UA 062.03164/2012), à FAPEAM, e ao CNPq, pela concessão de bolsas aos participantes envolvidos na pesquisa.

\section{REFERENCIAS}

Alvares CA, Stape JL, Sentelhas PC, de Moraes G, Leonardo J \& Sparovek G (2013) Köppen's climate classification map for Brazil. Meteorologische Zeitschrift, 22:711-728.

Azevedo GFC \& Marenco RA (2012) Growth and physiological changes in saplings of Minquartia guianensis and Swietenia macrophylla during acclimation to full sunlight. Photosynthetica, 50:86-94.

Atkin OK, Bruhn D, Hurry VM \& Tjoelker MG (2005) The hot and the cold: unravelling the variable response of plant respiration to temperature. Functional Plant Biology, 32:87-105.

Baker TR, Phillips OL, Malhi Y, Almeida S, Arroyo L, Di Fiore A, Erwin T, Higuchi N, Killeen TJ, Laurance SG, Laurance WF, Lewis SL, Monteagudo A, Neill DA, Vargas PN, Pitman NCA, Silva JNM \& Martinez RV (2004) Increasing biomass in Amazonian forest plots. Philosophical Transactions of the Royal Society of London B, 359:353-365.

Berry J \& Bjorkman O (1980) Photosynthetic response and adaptation to temperature in higher plants. Annual Review of Plant Physiology, 31:491-543.

Bjorkman O \& Demmig B (1987) Photon yield of $\mathrm{O}_{2}$ evolution and chlorophyll fluorescence characteristics at $77 \mathrm{~K}$ among vascular plants of diverse origins. Planta, 170:489-504.

Bonal D, Ponton S, Le Thiec D, Richard B, Ningre N, Herault B, Ogee J, Gonzalez S, Pignal M, Sabatier D \& Guehl JM (2011) Leaf functional response to increasing atmospheric $\mathrm{CO}_{2}$ concentrations over the last century in two northern Amazonian tree species: a historical $\delta^{13} \mathrm{C}$ and $\delta^{18} \mathrm{O}$ approach using herbarium samples. Plant, Cell and Environment, 34:1332-1344.

Brooks A \& Farquhar GD (1985) Effect of temperature on the $\mathrm{CO}_{2} / \mathrm{O}_{2}$ specificity of ribulose-1,5-bisphosphate carboxylase/oxygenase and the rate of respiration in the light. Planta, 165:397-406.

Camargo MAB \& Marenco RA (2012) Growth, leaf and stomatal traits of crabwood (Carapa guianensis Aubl.) in central Amazonia. Revista Árvore, 36:07-16.

Cienciala E, Kuèera J \& Malmer A (2000) Tree sap flow and stand transpiration of two Acacia mangium plantations in Sabah, Borneo. Journal of Hydrology, 236:109-120.

Cen YP \& Sage RF (2005) The regulation of Rubisco activity in response to variation in temperature and atmospheric $\mathrm{CO}_{2}$ partial pressure in sweet potato. Plant Physiology, 139: 979-990.

Costa GF \& Marenco RA (2007) Fotossíntese, condutância estomática e potencial hídrico foliar em árvores jovens de andiroba (Carapa guianensis). Acta Amazonica, 37:229-234.

Da Silva RP dos Santos J, Tribuzy ES, Chambers JQ, Nakamura S \& Higuchi N (2002) Diameter increment and growth patterns for individual tree growing in Central Amazon, Brazil. Forest Ecology and Management, 166:295-301.

Dawson TE, Burgess SS, Tu KP, Oliveira RS Santiago LS, Fisher JB Simonin KA \& Ambrose AR (2007) Nighttime transpiration in woody plants from contrasting ecosystems. Tree Physiology, 27:561-575.
Domingues TF, Martinelli LA \& Ehleringer JR (2007) Ecophysiological traits of plant functional groups in forest and pasture ecosystems from eastern Amazonia, Brazil. Plant Ecology, 193:101-112.

Domingues TF, Martinelli LA, Ehleringer \& JR (2014) Seasonal patterns of leaf-level photosynthetic gas exchange in an eastern Amazonian rain forest. Plant Ecology and Diversity, 7:189-203.

Doughty CE \& Goulden ML (2008) Are tropical forests near a high temperature threshold? Journal of Geophysical Research, 113:G00B07. DOI.

Doughty CE, Goulden ML, Miller SD \& da Rocha HR Circadian rhythms constrain leaf and canopy gas exchange in an Amazonian forest. Geophysical Research Letters, 33: L15404. DOI.

Evans J \& Poorter H (2001) Photosynthetic acclimation of plants to growth irradiance: the relative importance of specific leaf area and nitrogen partitioning in maximizing carbon gain. Plant, Cell \& Environment, 24:755-767.

Farquhar GD, Von Caemmerer S \& Berry JA(1980) A biochemical model of photosynthetic $\mathrm{CO}_{2}$ assimilation in leaves of $\mathrm{C}_{3}$ species. Planta, 149:78-90.

Fisher JB, Baldocchi DD, Misson L, Dawson TE \& Goldstein AH (2007) What the towers don't see at night: nocturnal sap flow in trees and shrubs at two AmeriFlux sites in California. Tree Physiology, 27:597-610.

Fisher JB, Malhi Y, Bonal D, Da Rocha HR, De Araujo AC, Gamo M, Goulden ML, Hirano T, Huete AR, Kondo H, Kumagai T, Loescher HW, Miller S, Nobre AD, Nouvellon Y, Oberbauer SF, Panuthai S, Roupsard O, Saleska S, Tanaka K, Tanaka N, Tu KP \& Von Randow C (2009) The land-atmosphere water flux in the tropics. Global Change Biology, 15:2694-2714.

Flexas J, Barbour MM, Brendel O, Cabrera HM, Carriquí M, Díaz-Espejo A, Douthe C, Dreyer E, Ferrio JP \& Gago J (2012) Mesophyll diffusion conductance to $\mathrm{CO}_{2}$ : An unappreciated central player in photosynthesis. Plant Science, 193:70-84.

Forster MA (2014) How significant is nocturnal sap flow? Tree Physiology, 34:757-765.

Friedlingstein P, Cox P, Betts R, Bopp L, Von Bloh W, Brovkin V, Cadule P, Doney S, Eby M, Fung I, Bala G, John J, Jones C, Joos F, Kato T, Kawamiya M, Knorr W, Lindsay K, Matthews HD, Raddatz T, Rayner P, Reick C, Roeckner E, Schnitzler KG, Schnur R, Strassmann K, Weaver AJ, Yoshikawa C \& Zeng N (2006) Climate-carbon cycle feedback analysis: Results from the C4MIP model intercomparison. Journal of Climate, 19:3337-3353.

Gatti LV, Gloor M, Miller JB, Doughty CE, Malhi Y, Domingues LG, Basso LS, Martinewski A, Correia CSC, Borges VF, Freitas S, Braz R, Anderson LO, Rocha H, Grace J, Phillips OL \& Lloyd J (2014) Drought sensitivity of Amazonian carbon balance revealed by atmospheric measurements. Nature, 506:76-80.

Goldstein G, Andrade JL, Meinzer FC, Holbrook NM, Cavelier J, Jackson P \& Celis A (1998) Stem water storage and diurnal patterns of water use in tropical forest canopy trees. Plant, Cell and Environment, 21:397-406

Goulden ML, Miller SD, Rocha HRd, Menton MC, Freitas HCd, Silva Figueira AM \& Sousa CAD (2004) Diel and seasonal patterns of tropical forest $\mathrm{CO}_{2}$ exchange. Ecological Applications, $14: 42-54$.

Graham EA, Mulkey SS, Kitajima K, Phillips NG \& Wright SJ (2003) Cloud cover limits net $\mathrm{CO}_{2}$ uptake and growth of a rainforest tree during tropical rainy seasons. Proceedings of the National Academy of Sciences USA, 100:572-576.

Grogan J \& Schulze M (2012) The impact of annual and seasonal rainfall patterns on growth and phenology of emergent tree species in Southeastern Amazonia, Brazil. Biotropica, 44:331-340. 
Houghton R, Skole D, Nobre CA, Hackler J, Lawrence K \& Chomentowski WH (2000) Annual fluxes of carbon from deforestation and regrowth in the Brazilian Amazon. Nature, 403:301-304.

Hozain MI, Salvucci ME, Fokar M \& Holaday AS (2010) The differential response of photosynthesis to high temperature for a boreal and temperate Populus species relates to differences in Rubisco activation and Rubisco activase properties. Tree Physiology, 30:32-44.

Iio A, Fukasawa H, Nose Y \& Kakubari Y (2004) Stomatal closure induced by high vapor pressure deficit limited midday photosynthesis at the canopy top of Fagus crenata Blume on Naeba mountain in Japan. Trees, 18:510-517.

INMET (2014) Estações automáticas: gráficos. Disponível em: <http:/ / w w w. in met.gov.br/portal/index.ph p r $=$ home/ page \&page $=$ rede_estacoes_auto_graf.>. Acessado em: 30/05/ 2014.

Jensen RG (1990) Ribulose 1,5-bisphosphate carboxylase/oxygenase: mechanism, activation and regulation. In: Dennis DT \& Turpin DH (Eds.) Plant physiology, biochemistry and molecular biology. Essex, Longman Scientific \& Technical. p.224-238.

Kavanagh KL, Pangle R \& Schotzko AD (2007) Nocturnal transpiration causing disequilibrium between soil and stem predawn water potential in mixed conifer forests of Idaho. Tree Physiology, 27:621-629.

Kaiser WM (1987) Effects of water deficit on photosynthetic capacity. Physiologia Plantarum, 71:142-149.

Larcher W (1995) Physiological plant ecology. $3^{\text {rd }}$ ed. New York, SpringerVerlag. 506p.

Lewis SL, Lloyd J, Sitch S, Mitchard ET \& Laurance WF (2009) Changing ecology of tropical forests: evidence and drivers. Annual Review of Ecology, Evolution, and Systematics, 40:529-549.

Lloyd J \& Farquhar GD (1996) The CO dependence of photosynthesis, plant growth responses to elevated atmospheric $\mathrm{CO}_{2}$ concentrations and their interaction with soil nutrient status .1. General principles and forest ecosystems. Functional Ecology, 10:4-32.

Lloyd J \& Farquhar GD (2008) Effects of rising temperatures and $\left[\mathrm{CO}_{2}\right]$ on the physiology of tropical forest trees. Philosophical Transactions of the Royal Society B: Biological Sciences, 363:1811-1817.

Lloyd J, Grace J, Miranda A, Meir P, Wong S, Miranda H, Wright I, Gash J \& McIntyre J (1995) A simple calibrated model of Amazon rainforest productivity based on leaf biochemical properties. Plant, Cell and Environment, 18:1129-1145.

Lobo FDA, de Barros M, Dalmagro H, Dalmolin Â, Pereira W, de Souza É, Vourlitis G \& Ortíz CR (2013) Fitting net photosynthetic lightresponse curves with Microsoft Excel-a critical look at the models. Photosynthetica, 51:445-456.

Loreto F, Centritto M \& Chartzoulakis K (2003) Photosynthetic limitations in olive cultivars with different sensitivity to salt stress. Plant Cell and Environment, 26:595-601.

Mafakheri A, Siosemardeh A, Bahramnejad B, Struik P \& Sohrabi Y (2010) Effect of drought stress on yield, proline and chlorophyll contents in three chickpea cultivars. Australian Journal of Crop Science, 4:580-585

Magalhães ND, Marenco RA \& Mendes KR (2009) Aclimatação de mudas de acariquara à alta irradiância. Pesquisa Agropecuária Brasileira, 44:687-694.

Magalhães NS, Marenco RA \& Camargo MAB (2014) Do soil fertilization and forest canopy foliage affect the growth and photosynthesis of Amazonian saplings? Scientia Agricola, 71:58-65.

Malhi Y \& Wright J (2004) Spatial patterns and recent trends in the climate of tropical rainforest regions. Philosophical Transactions of the Royal Society of London, 359:311-329.
Malhi Y, Nobre AD, Grace J, Kruijt B, Pereira MG, Culf A \& Scott S (1998) Carbon dioxide transfer over a Central Amazonian rain forest. Journal of Geophysical Research, 103:31593-31612.

Marks CO \& Lechowicz MJ (2007) The ecological and functional correlates of nocturnal transpiration. Tree Physiology, 27:577-584.

Marenco RA \& Lopes NF (2009) Fisiologia vegetal: fotossíntese, respiração, relações hídricas e nutrição mineral. $3^{\mathrm{a}}$ ed. Editora UFV, Viçosa. 486p.

Marenco RA, Gonçalves JFC \& Vieira G (2001) Leaf gas exchange and carbohydrates in tropical trees differing in successional status in two light environments in central Amazonia Tree Physiology, 21:13111318

Marenco RA, Neves TS, Camargo MAB, Dias DP, Costa GF \& Rodrigues JC (2007) Fotoinibição dinâmica da fotossíntese em árvores de dossel da Amazônia Central. Revista Brasileira de Biociências, 5:150-152.

Marenco RA, Nascimento HCS \& Magalhães NS (2014) Stomatal conductance in Amazonian tree saplings in response to variations in the physical environment. Photosynthetica. 52:493-500.

Martin B \& Ruiz-Torres NA (1992) Effects of water-deficit stress on photosynthesis, its components and component limitations, and on water-use efficiency in wheat (Triticum aestivum L). Plant Physiology, 100:733-739.

Medlyn B, Dreyer E, Ellsworth D, Forstreuter M, Harley P, Kirschbaum M, Le Roux X, Montpied P, Strassemeyer J \& Walcroft A (2002) Temperature response of parameters of a biochemically based model of photosynthesis. II. A review of experimental data. Plant, Cell and Environment, 25:1167-1179.

Mendes KR \& Marenco RA (2010) Leaf traits and gas exchange in saplings of native tree species in the Central Amazon. Scientia Agricola, 67:624-632.

Mendes KR \& Marenco RA (2014) Is stomatal conductance of Central Amazonian saplings influenced by circadian rhythms under natural conditions? Theoretical and Experimental Plant Physiology, 26:115-125.

Mendes KR, Marenco RA \& Magalhães ND (2013) Growth and photosynthetic use efficiency of nitrogen and phosphorus in saplings of Amazonian tree species. Revista Árvore, 37:707-716.

Monteith JL (1995) A reinterpretation of stomatal responses to humidity. Plant, Cell and Environment, 18:357-364.

Nascimento HCS \& Marenco RA (2013) Mesophyll conductance variations in response to diurnal environmental factors in Myrcia paivae and Minquartia guianensis in Central Amazonia. Photosynthetica, 51:457-464.

Nowak RS, Ellsworth DS \& Smith SD (2004) Functional responses of plants to elevated atmospheric $\mathrm{CO}_{2}-$ do photosynthetic and productivity data from FACE experiments support early predictions? New Phytology, 162:253-280.

Parry MAJ, Andralojc PJ, Khan S, Lea PJ \& Keys AJ (2002) Rubisco activity: Effects of drought stress. Annals of Botany, 89:833-839.

Quesada CA, Phillips OL, Schwarz M, Czimczik CI, Baker TR, Patino S, Fyllas NM, Hodnett MG, Herrera R, Almeida S, Alvarez Dávila E, Arneth A, Arroyo L, Chao KJ, Dezzeo N, Erwin T, Di Fiore A, Higuchi N, Honorio Coronado E, Jimenez EM, Killeen T, Lezama AT, Lloyd G, López-González G, Luizão FJ, Malhi Y, Monteagudo A, Neill DA, Núñez Vargas P, Paiva R, Peacock J, Peñuela MC, Peña Cruz A, Pitman N, Priante Filho N, Prieto A, Ramírez H, Rudas A, Salomão R, Santos AJB, Schmerler J, Silva N, Silveira M, Vásquez R, Vieira I, Terborgh J \& Lloyd J (2012) Basin-wide variations in Amazon forest structure and function are mediated by both soils and climate. Biogeosciences, 9:2203-2246

Saatchi S, Houghton R, Dos Santos Alvala R, Soares J \& Yu Y (2007) Distribution of aboveground live biomass in the Amazon basin. Global Change Biology, 13:816-837. 
Sage RF \& Kubien DS (2007) The temperature response of $\mathrm{C}_{3}$ and $\mathrm{C}_{4}$ photosynthesis. Plant Cell and Environment, 30:1086-1106.

Salati E (1987) The forest and the hydrological cycle. In: Dickinson RE (Ed.) The geophysiology of Amazonia: vegetation and climate interactions. New York, John Wiley and Sons. p.526.

Sanchez PA (1977) Properties and management of soils in the tropics. New York, John Wiley \& Sons. 618p.

Shimazaki KI, Doi M, Assmann SM \& Kinoshita T (2007) Light regulation of stomatal movement. Annual Review of Plant Biology, 58:219-247.

Singsaas EL, Ort DR \& DeLucia EH (2000) Diurnal regulation of photosynthesis in understory saplings. New Phytologist, 145:39-49.

Schwab K, Schreiber U \& Heber U (1989) Response of photosynthesis and respiration of resurrection plants to desiccation and rehydration. Planta, 177:217-227.

Tourneux C \& Peltier G (1995) Effect of water deficit on photosynthetic oxygen exchange measured using ${ }^{18} \mathrm{O}_{2}$ and mass spectrometry in Solanum tuberosum L. leaf discs. Planta, 195:570-577.

Townsend AR, Cleveland CC, Asner GP \& Bustamante MMC (2007) Controls over foliar N: Pratios in tropical rain forests. Ecology, 88:107118.

Townsend AR, Cleveland CC, Houlton BZ, Alden CB \& White JWC (2011) Multi-element regulation of the tropical forest carbon cycle. Frontiers in Ecology and the Environment, 9:9-17.

Tribuzy ES (2005) Variações da temperatura foliar do dossel e o seu efeito na taxa assimilatória de $\mathrm{CO}_{2}$ na Amazônia Central. Tese Doutorado. ESALQ, São Paulo. 77p.
Villar R, Held AA \& Merino J (1994) Comparison of methods to estimate dark respiration in the light in leaves of two woody species. Plant Physiology, 105:167-172.

Vitousek PM, Porder S, Houlton BZ \& Chadwick OA (2010) Terrestrial phosphorus limitation: mechanisms, implications, and nitrogenphosphorus interactions. Ecological Applications, 20:5-15.

Von Caemmerer S \& Quick WP (2000) Rubisco: physiology in vivo. In: Leegood RC, Sharkey TD \& Von Caemmerer S (Eds.) Photosynthesis: Physiology and Metabolism. Dordrecht, Kluwer Academic. p.85-113.

Wagner F, Rossi V, Stahl C, Bonal D \& Herault B (2012) Water availability is the main climate driver of neotropical tree growth. PLoS One, 7:e34074. DOI: 10.1371/journal.pone.0034074.

Wagner F, Rossi V, Aubry-Kientz M, Bonal D, Dalitz H, Gliniars R, Stahl C, Trabucco A \& Herault B (2014) Pan-tropical analysis of climate effects on seasonal tree growth. PLoS One 9: e92337. DOI: 10.1371/ journal.pone.0092337.

Warren CR (2008) Soil water deficits decrease the internal conductance to $\mathrm{CO}_{2}$ transfer but atmospheric water deficits do not. Journal Experimental Botany, 59:327-334.

Yamori W, Hikosaka K \& Way DA (2014) Temperature response of photosynthesis in $\mathrm{C}_{3}, \mathrm{C}_{4}$, and CAM plants: temperature acclimation and temperature adaptation. Photosynthesis Research, 119:101-117.

Zeppel M, Tissue D, Taylor D, Macinnis-Ng C \& Eamus D (2010) Rates of nocturnal transpiration in two evergreen temperate woodland species with differing water-use strategies. Tree Physiology, 30:9881000 . 